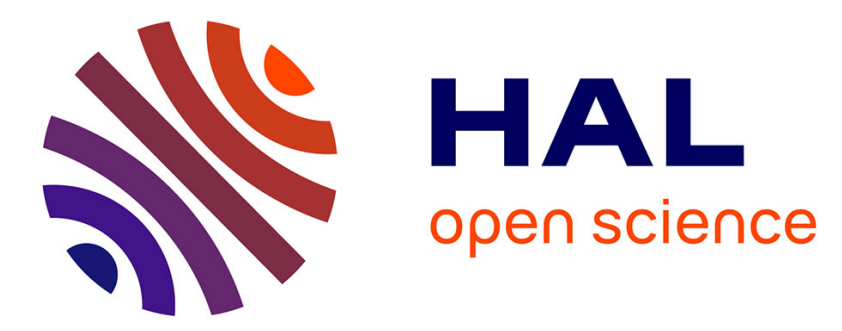

\title{
Update of Imaging in the diagnosis and management of axial spondyloarthritis
}

Krystel Aouad, Walter P Maksymowych, Xenofon Baraliakos, Nelly Ziade

\section{To cite this version:}

Krystel Aouad, Walter P Maksymowych, Xenofon Baraliakos, Nelly Ziade. Update of Imaging in the diagnosis and management of axial spondyloarthritis. Best Practice and Research: Clinical Rheumatology, 2020, 34 (6), pp.101628. 10.1016/j.berh.2020.101628 . hal-03162692

\section{HAL Id: hal-03162692 \\ https://hal.sorbonne-universite.fr/hal-03162692}

Submitted on 8 Mar 2021

HAL is a multi-disciplinary open access archive for the deposit and dissemination of scientific research documents, whether they are published or not. The documents may come from teaching and research institutions in France or abroad, or from public or private research centers.
L'archive ouverte pluridisciplinaire HAL, est destinée au dépôt et à la diffusion de documents scientifiques de niveau recherche, publiés ou non, émanant des établissements d'enseignement et de recherche français ou étrangers, des laboratoires publics ou privés. 


\section{Update of Imaging in the diagnosis and management of axial spondyloarthritis}

Krystel Aouad $^{1,2}$, Walter P. Maksymowych ${ }^{3}$, Xenofon Baraliakos ${ }^{4}$, Nelly Ziade ${ }^{2,5}$

Affiliations:

Krystel Aouad

Department of Rheumatology, Pitié-Salpêtrière Hospital, AP-HP, Paris, France

2 Saint-Joseph University, Faculty of Medicine, Beirut, Lebanon

krystel.aouad@hotmail.com

\section{Walter P. Maksymowych}

3 Department of Medicine, Division of Rheumatology, University of Alberta, 568A Heritage Medical Research Centre, Edmonton, Alberta T6G2R3, Canada

walter.maksymowych@ualberta.ca

\section{Xenofon Baraliakos}

4 Department of Rheumatology, Rheumazentrum Ruhrgebiet, Ruhr-University Bochum, Claudiusstr. 45, 44649 Herne, Germany xenofon.baraliakos@elisabethgruppe.de

\section{Nelly Ziade}

5 Department of Rheumatology, Hotel-Dieu de France Hospital, Beirut, Lebanon

2 Saint-Joseph University, Faculty of Medicine, Beirut, Lebanon nellziade@yahoo.fr 


\section{Abstract}

Imaging of the spine and sacroiliac joints has acquired a central role in the diagnosis and classification of axial spondyloarthritis (axSpA) at the earliest phases of the disease. New definitions of specific imaging lesions, particularly in magnetic resonance imaging (MRI), have been recently updated and revised by the ASAS MRI working group to reach a standardized understanding and diagnosis of axSpA among rheumatologists. Recognizing the misleading pitfalls of MRI lesions and differential diagnosis also represents an essential issue in clinical practice to avoid false-positive findings and establish the diagnosis of axSpA with careful regard to the clinical context, clinical signs, and biological tests.

This review summarizes the current evidence on the different imaging modalities of the sacroiliac joints and the spine with their application in the clinical setting of SpA, their main pitfalls as well as a highlight on the newest emerging imaging techniques.

Keywords: imaging, axial spondyloarthritis, diagnosis, management. 


\section{Introduction}

Imaging of the sacroiliac joints (SIJ) and the spine has gained a pivotal role in clinical practice for the recognition of early axial spondyloarthritis as no unique reliable serological marker is available. Even though radiography is still the first imaging tool used to capture structural damage suggestive of sacroiliitis, magnetic resonance imaging (MRI) is a more accurate tool and has become a major asset in the early diagnosis of spondyloarthritis (SpA) and a surrogate marker for prognosis and monitoring of disease activity in trials[1,2].

Over the past decade, understanding the natural development of different lesion types of the spine has increased significantly, and analyzing MRI lesions over time has been of great value in the interpretation of pathophysiological mechanisms [3,4]. It has become clear that inflammatory lesions are visualized on MRI long before structural lesions are detected on conventional radiography[5]. On MRI scans, bone marrow edema (BME)/osteitis in subchondral bone is still considered to be indicative of active inflammation of the sacroiliac joints (SIJ) in early and later stages of axial SpA (axSpA)[6] and an anchor element of the Assessment in SpondyloArthritis international Society (ASAS) classification criteria of axSpA [7]. In contrast, erosions and ankylosis indicate structural damage, which may occur relatively early in disease. The clear presence of BME/osteitis on MRI scans is detectable in early stages before structural damage is seen on radiography and computed tomography (CT) [8].

Nevertheless, for clinicians, the challenge remains in the proper interpretation of imaging findings and more specifically what really constitutes a "positive MRI"[9]. Recent comparative studies on athletes, pregnant women, and chronic low back pain patients [10-12] have raised awareness of the multiple misleading pitfalls and controversies that can occur in the evaluation of imaging with an emphasis on the ability to differentiate mechanical stress changes from pathological MRI lesions in SpA patients.

In 2015, the EULAR task force presented recommendations for the use of imaging modalities in SpA in clinical practice [13]. However, since 2015, new evidence has become available with data

on specificity and sensitivity of MRI imaging findings in SpA, an updated consensus for MRI lesion definitions[14], improvement in MRI techniques and sequences for better imaging 
performance[6] as well as the emergence of new imaging tools such as whole-body MRI and 18Ffluoride PET-CT $[1,15]$.

This review provides a comprehensive overview of the different imaging tools with updated standardized protocols and thresholds in the diagnosis of axSpA of the SIJ and the spine as well as a highlight on the newest imaging modalities for axSpA monitoring and management.

\section{Imaging of the sacroiliac joints in axial spondyloarthritis}

\section{Conventional radiography of the sacroiliac joints}

Conventional radiography $(C R)$ of the sacroiliac joints is the first imaging modality for the assessment of a patient with clinical suspicion of axSpA, despite its low sensitivity, specificity, and reliability. Radiographic structural changes are sclerosis, erosions, pseudo-widening, bony bridges, or ankylosis. The 1984 modified New York classification criteria [16] incorporate a radiographic grading system used to assess structural lesions. The radiographic criterion for classification of ankylosing spondylitis is met if there is bilateral sacroiliitis grade $\geq 11$ or unilateral sacroiliitis grade III or IV. A single view of the SIJ is recommended. This may be an anteroposterior (AP) view showing both the pelvis and the hip joints or a modified view in which the $x$-ray tube is angulated $30^{\circ}$ to $35^{\circ}$ cephalad (Ferguson view) $[17,18]$. Additional oblique views to reduce structural overlap result in more radiation and do not enhance diagnostic accuracy [19].

\section{Computed tomography of the sacroiliac joints}

Computed tomography (CT) has superior sensitivity and specificity compared to CR in the visualization of subtle bone erosions, sclerosis, and ankylosis at the SIJ, posterior elements of the spine, and costovertebral joints [20]. Even though CT results in an increased amount of radiation compared to $C R$, it can be useful in patients with negative $C R$ and unable to undergo MRI [13] or when there are equivocal MRI abnormalities [21]. However, it does not detect inflammatory lesions in early axSpA before structural damage occurs. 
Low- dose CT (IdCT)has emerged recently as an alternative to conventional CT in the imaging of the SIJ and spine. LdCT of the SIJ had a superior diagnostic accuracy to SIJ radiography with similar mean radiation exposure (0.51 mSv compared with $0.52 \mathrm{mSv}$ respectively) [22]. However, it is still unknown whether IdCT would have higher sensitivity and specificity than conventional full dose CT for the detection of structural lesions and quantification of syndesmophytes [22]. Studies with abdominal CT scans done for another medical reason in patients with ankylosing spondylitis, have shown the possibility to detect SIJ abnormalities related to sacroiliitis with good sensitivity (Se: 0.71) and excellent specificity (Spe: 1) compared to SIJ CT [22].

\section{Magnetic resonance imaging of the sacroiliac joints}

MRI of the SIJ is the best tool for the evaluation of early inflammatory lesions. This examination should include T1-weighted (T1W) and fluid sensitive sequences such as T2-weighted fatsuppressed (T2-FS), T2-weighted Dixon, and short-tau inversion recovery (STIR). For sacroiliitis, intravenous gadolinium contrast-enhanced imaging (such as T1-FS post-Gd) is not recommended by EULAR [13] as it has not been shown to increase diagnostic accuracy and it is costly. However, in doubtful cases, it can be used for differential diagnosis.

\subsection{ASAS definition for a positive MRI}

In 2009, ASAS defined a positive MRI i.e., active sacroiliitis, as "highly suggestive of spondyloarthritis" if BME was seen in the same SIJ quadrant on at least two consecutive slices of an MRI scan or if there was more than one BME lesion present on a single slice $[6,23]$. In 2016, the ASAS MRI working group updated the definition of a positive MRI adding that BME observed on STIR or T2-FS or osteitis on T1-FS post-Gd must be clearly present in a typical anatomical location in the subchondral bone marrow and the appearance should be highly suggestive of SpA [6]. In particular, the importance of contextual interpretation of both fat-suppressed and T1W scans was emphasized. This definition was designated for classification purposes rather than for axSpA diagnosis. In the absence of BME, the other inflammatory or structural MRI lesions were not considered sufficient to define "active sacroiliitis on MRI" [6].

\subsection{MRI Scoring system}


The extent of BME can be quantified according to the Spondyloarthritis Research Consortium of Canada (SPARCC) scoring system [24]. Semicoronal slices are assessed on fat-suppressed scans from anterior to posterior. The six with the most severe inflammation are selected and each SIJ is divided into 4 quadrants: the upper and lower sacrum and the upper and lower ilium. Each quadrant is assigned a score of 1 for the presence of BME or 0 for the absence of BME. Each SIJ on each slice is scored for the presence of "deep" lesions (a homogeneous, unequivocal increase in signal extending $\geq 1 \mathrm{~cm}$ from the articular surface) or "intense" lesions (high signal compared to sacral blood vessels). Scoring for 6 consecutive slices leads to a maximum score of 48 for BME, 12 for intensity, 12 for depth, and 72 in total [24].

\subsection{Recommended MRI sequences for sacroiliac joints}

Simultaneous evaluation of T1W and fat-suppressed sequences (STIR, T2-FS) MRI sequences of the SIJ is recommended as the appropriate scanning protocol for axSpA diagnosis by the European Society of Musculoskeletal Radiology (ESSR) Arthritis Subcommittee[25]. The SIJ should be visualized in two perpendicular planes: oblique coronal (parallel to the posterior surface of the S2 vertebral body) and oblique axial (perpendicular to the oblique coronal slice) [25].

The T1W sequence detects the signal from fat (hyperintense signal on T1W) that contrasts with the cortical bone (hypointense signal on T1W). Hence, T1W is used to evaluate structural damage, mostly bone erosion [2]. As for fluid sensitive sequences, T2-FS sequences have suggested higher detection of BME compared to PD-STIR in the SIMACT study [26]. MRI can perceive various lesions indicating active inflammation/signs of disease activity (typically BME/osteitis) or structural damage (bone erosion, fat lesion, sclerosis, backfill, and new bone formation/ankylosis). Their standardized definitions were recently revised and validated by the ASAS MRI-working group [14,25]. New MRI lesions seen in axSpA were recently described such as joint space fluid or fat metaplasia in an erosion cavity (described in Figure 1 and 2) [14].

\subsection{Diagnostic utility of MRI lesions}

Altogether, defining a reference standard in imaging for axSpA remains a real challenge. A recent systematic review on MRI diagnostic performance reported an increased specificity when other lesions such as erosion and fat lesion were associated with BME[27]. In five studies, SIJ erosions 
revealed good specificity but poor to moderate sensitivity with a higher sensitivity of erosions in AS than in non-radiographic axSpA [27]. As for the utility of SIJ fat lesion, four studies have shown a low to moderate sensitivity $(0.15-0.70)$ but moderate to high specificity $(0.72-0.95)$ for the diagnosis of axSpA with increased specificity in AS than in non-radiographic axSpA [27]. Concerning the other MRI lesions reported in three studies including ankylosis, sclerosis, capsulitis, fluid signal (Figure 1 and 2), backfill and vacuum phenomenon (presence of gas in the

joint space associated with degenerative diseases) have demonstrated limited diagnostic performance $[27,28]$.

\subsection{Prognostic value}

It is increasingly acknowledged today that MRI has prognostic value in the prediction of radiographic damage in SpA [29]. In the DESIR cohort study, BME on the SIJ-MRI was identified as a predisposing factor for progression to radiographic sacroiliitis 5 years later [30]. Further, the association of SIJ-BME with other parameters such as HLAB27 positivity and elevated C-reactive protein (CRP), increased the likelihood of progression from non-radiographic to radiographic axSpA from $1.2 \%$ to $18.4 \%$ [30]. Also, a recent histopathological analysis of 193 SIJ biopsies of patients with axSpA showed that the presence at baseline of cartilage pannus/granulation tissue invasion and endochondral ossification were both risk factors for progression to radiographic sacroiliitis [31].

\section{Imaging of the spine in axial spondyloarthritis}

Spinal changes may be clinically relevant for diagnosing axSpA because they usually represent more advanced stages of the disease. However, because only a limited proportion of the patients with axSpA were reported to have spinal changes without distinct SIJ changes, the involvement of the spine has not been part of any classification criteria for axSpA so far [32]. 


\section{Conventional radiographs of the spine}

Conventional radiographs (CRs) of the spine are usually the first imaging modality ordered for the assessment of a patient with low back pain of any cause in clinical practice.

\section{1- Sensitivity}

In the early phases of the disease, CR have low sensitivity to detect axSpA lesions which makes them of very limited utility for early diagnosis. Instead, they are used to evaluate other differential diagnoses.

In more advanced phases of the disease, the radiographic abnormalities in the spine can be categorized into osteo-destructive (erosions of the vertebral corner and the vertebral endplate) and hyperproliferative (enthesophytes, vertebral squaring, disc calcifications, spondylophytes, syndesmophytes, bony bridging, vertebral ankylosis) pathologic changes. These may rarely be evident without the involvement of the SIJ; therefore, the inclusion of routine radiography of the spine in diagnostic evaluation is not useful [3].

The time required for structural lesions of the spine to develop is still unknown, with significant individual variability among patients [33]. Globally, such structural changes have been reported to be present in more than $50 \%$ of patients within the first 16 years of AS [34].

\section{2- $\quad$ Specificity}

Syndesmophytes are typical axSpA lesions characterized by their characteristic vertical growth, which may lead to bridging phenomena in the pre-discal region between the intervertebral disc and the anterior longitudinal ligament [35]. However, they may be confused with spondylophytes, which are of degenerative etiology but can also be found in patients with axSpA, particularly in those with longer disease duration.

\section{3- Prognostic value}

The presence of syndesmophytes at baseline is a poor prognostic marker as it is associated with the development of additional syndesmophytes and structural progression in prospective cohorts[33]. In patients with early axSpA in the DESIR cohort, radiographic progression in the 
spine at 5 years was evident in $42 \%$ of patients who had a syndesmophyte at the start of the study compared with $4 \%$ of patients without baseline syndesmophytes in this cohort [36]. Therefore, the presence of a syndesmophyte at baseline, or during follow-up, may be a factor in the decision of stepping up therapy towards biologics, particularly in patients who have failed NSAIDs.

In addition to inflammatory spinal changes, structural changes on CR may also play an important role in the evaluation of medical interventions because the effects of NSAIDs or biologic agents on new bone formation are relevant in clinical studies on patients with axSpA.

\section{4- Scoring}

The first described scoring method for assessing radiographic progression in the spine in patients with axSpA was the Stoke Ankylosing Spondylitis Spine Scoring (SASSS)[37] followed by the Bath Ankylosing Spondylitis Radiology Index (BASRI)[38]. Comparisons of the scoring methods have confirmed that the modified SASSS (mSASSS) method is the most valid, feasible, and responsive plain radiographic scoring method[39].

In the mSASSS method[40], lateral radiographs of the cervical and lumbar spine are evaluated. A score of 1 is assigned to any vertebral corner erosion, squaring of the vertebral body, or vertebral corner sclerosis, a score of 2 is assigned to a vertebral corner syndesmophyte and a score of 3 is assigned to a vertebral corner with intervertebral ankylosis present. The total score for the 12 anterior vertebral corners including each cervical and lumbar spinal segment, therefore, ranges from 0 to 36. Spinal radiographs are typically scored from at least two-time points at least 2 years apart. Several studies of axSpA cohorts have shown that the average mSASSS progression is 1 unit per year when radiographs are read in known time sequence and 1 unit every 2 years when read blinded to the time sequence [41,42]. A 2-year follow-up is required before changes can be reliably detected with this method and so detecting disease modification in the 12-16 week time frame of placebo-controlled trials is not possible. A working group has also developed a calibration module for mSASSS that includes standardized definitions and methodology for scoring; its use led to improved reliability of the mSASSS method [43]. A modification of the mSASSS method to include the lowest four thoracic vertebral corners (lower edge of T10 to upper 
edge of T12) has also been attempted with the aim of improving its sensitivity to change, given the high frequency of spinal lesions at the thoracolumbar junction on MRI [44]. However, this modification did not improve the sensitivity to change of the mSASSS method when used to assess either patients with well-established SpA or patients with early axSpA (that is, patients from the DESIR cohort). The lower thoracic spine is often difficult to visualize owing to beam collimation for the lumbar spine combined with lumbar lordosis, which results in poor reliability in detecting change.

A further modification of the mSASSS method included the addition of the cervical facet joints [45]. Compared with the original mSASSS method, this modified mSASSS method detected more patients with definite damage at baseline (61\% versus 57\%) and more patients with definite progression after 4 years (55\% versus $48 \%$ ).

\section{5- Limitations}

The visibility of the C7-T1 (the cervicothoracic junction) and the L5-S1 (the lumbosacral joint) spinal segments is often poor and visualizing the thoracic spine is not possible because of overlapping soft and bony structures. Correct interpretation may be additionally limited due to scoliosis or kyphosis. Also, lateral CRs only show an over projection of the medial and lateral part of a vertebra, and the posterior corners on the lateral view of the CR cannot be assessed reliably. Moreover, CR are associated with irradiation, which may be a limitation, especially in juvenile forms of axSpA.

\section{6- Diagnostic utility}

CRs are the gold standard for the assessment and quantification of structural spinal changes, and thus are useful to assess the course of the disease and the damage that has already occurred.

\section{Low-dose CT of the spine}

Low-dose CT (IdCT) has also been described for the spine. Complete assessment of the spine is possible using an effective radiation dose of $4 \mathrm{mSv}$ as compared with $8 \mathrm{mSv}$ for assessment of 
the thoracic and lumbar spine[46]. This imaging modality has been employed to quantify the structural progression of axSpA in research but is not yet recommended for diagnostic evaluation. In 50 patients with AS in the Sensitive Imaging in Ankylosing Spondylitis cohort, lateral cervical, and lumbar spine CR and whole spine IdCT were obtained at baseline and 2 years. LdCT, covering the whole spine, detected nearly five times more new or growing syndesmophytes compared with $\mathrm{CR}$, most being found in the thoracic spine. The biggest advantages of IdCT were the ability to analyze the thoracic spine and the opportunity to analyze the growth of syndesmophytes in any plane, correcting for spinal curvatures, particularly at the posterior rim. Discrimination between treatments and testing if a shorter interval for IdCT can pick up sufficient change remain to be evaluated.

\section{Magnetic resonance imaging of the spine}

\section{1- Sensitivity}

Spine MRI is considered the most sensitive method for the detection of inflammatory lesions related to axSpA $[47,48]$. It can be used for the identification and quantification of active spinal lesions, where it has proved superior compared with other imaging techniques. Typical findings of disease activity when using spinal MRI in patients with axSpA are spondylitis, inflammation of the facet joints, and (aseptic) spondylodiscitis. Also, the lateral parts of the vertebral bodies and facet joint region should be assessed with the spinal images, because they are frequently affected in AS, and preferentially involved early in the course of the disease $[49,50]$.

Spinal MRI can also be used as a response tool for biological treatment, and a possible predictor of response to therapy. In an MRI study from patients with active AS treated with tumor necrosis factor inhibitors (TNFi) who participated in randomized controlled trials, the likelihood ratio (LR) for the achievement of BASDAI 50 was increased in patients with widespread inflammation of the spine as per a Berlin MRI spine score >11 (LR 6.7) [51].

T1-weighted (T1W) MRI has also been successfully used to assess structural changes [52]. However, a significant inter-reader variability is noted, especially among less experienced readers. 


\section{2- Specificity}

Similar to the SIJ, BME of spinal structures is not exclusive to axSpA but may also occur in other diseases. The most important differential diagnoses are degenerative/mechanical lesions, blood vessels, and hemangioma, fractures, metastases, or bacterial inflammation[3]. Degenerative lesions in the spine are common, even in young patients who have had a short duration of symptoms and can include vertebral corner inflammatory and fat lesions. On the other hand, inflammation in the costovertebral joints has a high specificity (>90\%) for the diagnosis of axSpA but sensitivity is inadequate $(<20 \%)[53,54]$.

\section{3- Prognostic value}

Several prospective studies have examined the link between inflammation at a vertebral corner and the subsequent formation of new bone as detected on radiography [55-58]. Evidence from these studies suggests that the vertebral corners where inflammation transforms into fat metaplasia are more likely to be associated with new bone formation. Biopsies were obtained from 21 patients with AS and 18 patients with degenerative disc diseases during planned surgery from vertebral edges where MRI signals of fatty lesions (FL) were detected [59]. FL corresponded to the presence of adipocytes, resulting in a change of cellular homeostasis towards the diminution of osteoclasts in the bone marrow of patients with AS. Consequently, the reparative response to inflammation, and not inflammation itself, might be the primary factor that predicts ankylosis. The presence of such MRI lesions in the SIJ joints and spine are may be a relevant factor when deciding whether to intensify treatment with the addition of a biologic drug, especially in young patients with active disease despite NSAID therapy.

\section{4- Definition of a positive spine MRI lesion}

The recommended approach for imaging of the spine in patients with axSpA is a T1W and a fatsuppressed MRI scan in the sagittal plane[25]. Fat-suppressed MRI scans can detect axSpA features such as spinal inflammatory lesions in the bone marrow of vertebral corners, adjacent to vertebral endplates, at costovertebral, facet, and costotransverse joints and in spinous 
processes, as well as in soft tissues at the entheses. Fat metaplasia might be seen in the bone marrow at the same locations on T1W scans.

The ASAS/OMERACT MRI working group has provided a consensus definition for MRI findings of the spine indicative of $\operatorname{axSpA}[48]$. This consensus statement concludes that inflammation in three or more anterior or posterior vertebral corners on at least two consecutive sagittal slices should be regarded as highly suggestive of $\operatorname{axSpA}$, particularly in patients of younger age when degenerative changes are less frequently expected. In general, several studies demonstrated that lower thresholds for the number of inflammatory lesions resulted in reasonable sensitivity but poor specificity; increasing the threshold improved specificity but worsened sensitivity [53,6062].

Regarding structural changes, fat metaplasia at several vertebral corners may also be indicative of axSpA. Detection of fat metaplasia at vertebral corners, particularly if present at several sites, increases the likelihood of axSpA, especially in younger patients, and is also associated with future radiographic progression at the affected vertebral corners [57].

Characteristic lesions in the spine of patients with axSpA as depicted by MRI are shown in Figure 3.

\section{5- MRI scoring systems}

Two methods of spinal inflammation assessment using fat-suppressed MRI scans have been widely used in clinical trials over the past several years $[63,64]$. Both methods score BME in the vertebral bodies on sagittal scans according to disco-vertebral units (DVU), each unit being delineated by two horizontal lines across the middle of the adjacent vertebrae.

The Berlin method scores the degree of BME according to the percentage volume of the DVU affected with BME (scoring range 0-3 per DVU). The SPARCC method divides the DVU into quadrants and records the presence or absence of BME on three consecutive sagittal slices and adds a weighting for intensity and depth of BME (scoring range 0-18 per DVU). Both the Berlin and SPARCC methods were able to discriminate between active therapy and placebo at 12-16 weeks in clinical trials of both AS and nr-axSpA [65-71]. 
A third method, the Canada-Denmark score, assesses the presence or absence of inflammation in vertebral bodies as well as the lateral and posterior segments of the spine[72]. As this anatomy-based method can also score structural lesions in the spine, in addition to BME, analysis of associations between different lesions on MRI is possible. Such analysis might further scrutinize the effects of potential disease-modifying therapies at different stages in the evolution of lesions from inflammation, to fat metaplasia, to new bone formation.

\section{6- Diagnostic utility}

Spinal MRI adds little incremental value to sacroiliac joint assessment alone in the diagnostic evaluation of patients with axSpA. In a Swiss-Canadian study of two cohorts (A and B, which together comprised 130 patients with undiagnosed back pain and a suspected diagnosis of axSpA, and 20 healthy individuals), sacroiliac joint and spine MRI assessments were conducted independently 6 months apart[73]. Of the patients with clinically suspected nr-axSpA who were negative for axSpA on sacroiliac joint MRI, $15.8 \%$ and $24.2 \%$ of those in cohorts $A$ and $B$, respectively, were categorized as having axSpA following global evaluation of the combined MRI scans. However, of the patients with nonspecific back pain, $26.8 \%$ and $11.4 \%$ of those in cohorts $A$ and $B$, respectively, and $17.5 \%$ of the healthy volunteers who were negative for axSpA on sacroiliac joint MRI, were falsely recategorized as having SpA by the combined MRI analysis. Also, data from the SPACE cohort[60], showed that the ASAS definition of a positive spine MRI did not have any useful diagnostic utility. The presence of inflammation in at least five corner lesions had a specificity of $\sim 95 \%$ and a sensitivity of $14 \%$. The presence of five corner lesions with fat metaplasia performed equally well as a cut-off in the SPACE cohort study. However, when these cut-offs were assessed in 541 and 650 patients with chronic back pain from the SPACE and DESIR cohorts, respectively, only $1 \%$ and $2 \%$ of patients without radiographic or MRI-detected sacroiliitis had at least five inflammatory and/or fat metaplasia corner lesions in the spine[74]. In general, spinal MRI may enhance the diagnostic sensitivity for axSpA by $15-20 \%$ in patients presenting with undiagnosed back pain where the MRI of the SIJ is considered equivocal or normal[73]. However, this is associated with a similar increase in false-positive diagnoses and a decline in specificity because vertebral corner BME and fat metaplasia can be observed in healthy 
individuals and those with nonspecific back pain and degenerative disorders. Consequently, routine MRI of the spine and SIJ is not recommended.

Data from the DESIR cohort has shown that MRI inflammation is more frequently observed in spinal segments that are symptomatic[75]. However, a later Dutch study from 2016 investigated spinal imaging findings together with localization of pain in patients from the SPACE cohort and found that spinal pain correlated significantly with imaging findings of degenerative lesions and that axSpA spinal lesions were not associated with pain[76].

Therefore, spinal MRI could be considered in addition to the assessment of the SIJ in certain clinical settings such as in patients with IBP with high clinical suspicion of axSpA, with a substantial component of pain in the interscapular region and where a major treatment decision is pending. In established axSpA, spine MRI may have a role in the differential diagnosis of exacerbations of axial symptomatology in patients with previously stable symptoms. It may support the decision whether these symptoms reflect the failure of therapy or an alternate source of pain such as degenerative or prolapsed disc pain. Whether spinal MRI has a role in tailoring a treat-to-target strategy and prevention of structural damage remains to be confirmed [77].

\section{Bone density testing}

It has been established that patients with axSpA have an increased risk of osteoporosis and fractures $[78,79]$. Persistent systemic inflammation might be one of the etiologic factors responsible for bone loss, which is most frequently measured by using dual-energy X-ray absorptiometry (DXA) [79]. In the DESIR cohort, bone loss at the lumbar spine and hip was observed in half of the patients with early axSpA over 5 years. Intriguingly, MRI inflammation at baseline was not correlated to this bone loss. On the other hand, another interesting observation is that TNF-inhibitors can increase BMD at the lumbar spine and total hip in patients with AS [80]. Yet, the effect of TNF-inhibitors on bone density is still unclear. Besides, it has been raised whether the alteration of BMD at the lumbar spine is linked to regional bone metabolism at the vertebral corners. To address this hypothesis, a study has investigated the correlation between bone activity at the vertebral corners and bodies using ${ }^{18} \mathrm{~F}$-fluoro-deoxyglucose positron emission 
tomography $\left({ }^{18} \mathrm{~F}-\mathrm{FDG}\right.$ PET) and BMD at each vertebral level from L1 to L4 [81]. A positive correlation was found between 18F-fluoride SUVmax uptake at the vertebral corners and conventional BMD of the lumbar vertebra ( $y=0.402, p=0.005)$; however, the correlation was not significant between vertebral bodies uptake and conventional BMD [81]. These findings suggest that BMD at the lumbar spine is affected by the osteoblastic activity at the vertebral corner. Therefore, a cautious interpretation of BMD on DXA should be undertaken in patients with axSpA.

\section{Clinical application of imaging in diagnosis and monitoring in axial}

\section{spondyloarthritis}

\section{Clinical application of imaging in the diagnosis of axSpA}

Detection and definition of patients with early axSpA, when treatment may be more effective, remains a continuous challenge. Diagnosis is often made years after symptoms develop [82] when radiographic damage is first noted.

\section{1- Clinical application of conventional radiography of the pelvis in the diagnosis of axSpA}

Pelvic radiography remains the cornerstone of the diagnostic evaluation of axSpA in clinical settings. In general, conventional radiographs of the SI joints are recommended by EULAR as the first imaging method to diagnose sacroiliitis as part of axial SpA [13]. They should be particularly considered in patients of less than 45 years of age with chronic back and/or buttock pain who present with symptoms suggesting an inflammatory basis to the symptomatology. The presence of SpA-related features such as iritis, psoriasis, and colitis and/or a family history of SpA should prompt the consideration of this diagnosis and evaluation by pelvic radiography.

An AP view of the SIJ is sufficient and additional views, such as dedicated oblique views, do not materially enhance the diagnostic utility. In Ferguson's view of the SIJ, the X-ray beam is projected 
$30-35^{\circ}$ cranial centered to the mid-portion of the pelvis. In this view, the symphysis pubis overlaps the sacrum and does not obscure the SIJ. This may provide an enhanced view of the SIJ; however, the diagnostic utility of this view has not been formally demonstrated to be superior to the AP view[3].

Even when radiographs are used to make the diagnosis of axSpA, the agreement among readers is only fair to moderate[83,84]. Therefore, the rheumatologist and the radiologist must communicate together about the clinical context of a given case, to avoid under- or overdiagnosis of axSpA based on CR.

It is important to keep in mind that CR has limited value in the early stages of the disease, because of its poor sensitivity and specificity caused by its inability to detect inflammatory activity[85]. In case the pelvis radiography is normal in a symptomatic patient with a high clinical index of suspicion of axSpA, repeating the radiography within 5 years is not beneficial. Prospective studies of patients presenting with clinical features of SpA but without definite radiographic changes have shown that only $10-15 \%$ develop radiographic sacroiliitis after 2 years, approximately $40 \%$ develop after 5 years, and approximately $60 \%$ develop after 10 years[86-89]. A more appropriate next step would be to order a pelvic MRI, particularly if the patient is young with short symptom duration[13].

\section{2- Clinical application of conventional radiography of the spine in the diagnosis of axSpA}

Radiographic abnormalities in the spine without the involvement of the SIJ are infrequent; therefore, the inclusion of routine radiography of the spine in the diagnostic evaluation may not be useful. However, spine radiographs may be valuable in the early diagnostic phase of axSpA to rule-out differential diagnoses and, especially, to identify new bone formation (syndesmophyte) since this is a poor prognostic factor for future bone formation. In that case, treatment may be stepped up according to the patient's forecasted risk of structural progression, especially given the emergence of data suggesting that biotherapies may retard this progression [90].

\section{3- Clinical application of SIJ MRI in the diagnosis of axSpA}


MRI can detect SIJ abnormalities at a much earlier time point compared to CR, which has allowed for the identification of axSpA early in its disease course[91].

According to the 2015 EULAR recommendation[13], MRI of the SIJ is recommended if the diagnosis of axial SpA cannot be established based on clinical features and conventional radiography, and axSpA is still suspected. In certain cases, such as young patients and those with short symptom duration, MRI of the SI joints is an alternative first imaging method to the SIJ CR. On MRI, both active inflammatory lesions (primarily BME) and structural lesions (such as bone erosion, new bone formation, sclerosis, and fat lesion) should be considered. Although erosions are not included in the classification criteria, they may be seen in a substantial proportion of patients with $\mathrm{nr}$-axSpA and can be detected on MRI of the SIJ before they are seen on radiography[92]. Also, the European Society of Musculoskeletal Radiology similarly advocated for the use of MRI when axSpA is suspected and radiographs are negative or equivocal [93]. Patients with nr-axSpA who have clinically active disease but who lack objective evidence of inflammation on SIJ MRI initially may benefit from subsequent retesting for inflammation to guide treatment. In a post hoc analysis of the randomized, double-blind ABILITY-1 study, $31 \%$ of patients without SIJ MRI inflammation at baseline subsequently developed inflammation after 12 weeks of placebo[94]. In addition to its diagnostic role, SIJ MRI also has a role in disease prognosis as inflammation and fat metaplasia might predict new bone formation in the spine. Moreover, the detection of inflammation in the sacroiliac joints on MRI is also helpful in selecting patients with $\mathrm{nr}$-axSpA for treatment with a TNF inhibitor, whereas the absence of inflammation on MRI and a normal serum C-reactive protein concentration predicts failure of treatment.

\section{4- Clinical application of spine MRI in the diagnosis of axSpA}

Unlike the SIJ MRI, spine MRI is not recommended for the diagnosis of axSpA[13]. Spinal MRI may enhance the diagnostic sensitivity for axSpA by only $15-20 \%$ in patients presenting with undiagnosed back pain where the MRI of the SIJ is considered equivocal or normal. But it is associated with a similar increase in false-positive diagnoses and a decline in specificity because vertebral corner BME and fat metaplasia can be observed in healthy individuals and those with 
nonspecific back pain and degenerative disorders[73]. Consequently, routine MRI of the spine and SIJ is not recommended. [74].

Fat lesions on MRI may be used to predict the development of new radiographic syndesmophytes, thus contributing to tailored therapy. These are factors to consider when deciding on the intensification of treatment to biologic agents, especially in young patients with active symptoms despite NSAID therapy. Also, extensive MRI inflammatory activity (BME), particularly in the spine, might be used as a predictor of good clinical response to anti-TNF-alpha treatment in axial SpA. Thus, MRI might aid in the decision for initiating TNFi therapy, in addition to clinical examination and CRP.

\section{5- Clinical application of other imaging modalities in the diagnosis of axSpA}

Imaging modalities, other than conventional radiography and $\mathrm{MRI}$ are generally not recommended in the diagnosis of axial SpA. CT may provide additional information on structural damage if conventional radiography is negative and MRI cannot be performed, in the case of a patient who is sufficiently symptomatic to warrant escalation to costly biological therapy but there is still diagnostic doubt. Scintigraphy and ultrasound are not recommended for the diagnosis of sacroiliitis as part of axial SpA [13]. A comparison of the advantages and limitations of the imaging techniques most widely used in the sacro-iliac and spine in axSpA is presented in Table 1.

\section{Monitoring}

Using imaging techniques to monitor disease activity and progression has been of recent interest in axSpA. To monitor structural progression, CR of the spine can be performed on a 2-year basis. $\mathrm{CT}$, and more particularly IdCT, may also seem advantageous to follow-up the underlying structural damage with better performance than CR [1].

As for monitoring disease activity, MRI, rather than CR and CT -that only show structural lesions, has been used in clinical trials and has shown a considerable reduction of inflammatory lesions 
over time under biologic treatment [67,95-102]. Moreover, a significant correlation between clinical disease activity and inflammatory lesions on MRI was observed in the early phases of the disease. Data from the DESIR cohort including 167 early SpA patients (mean symptom duration $<2$ years), showed a significant correlation (in men but not in women) between SIJ inflammation on MRI and ASDAS ( $\beta=2.4,95 \% \mathrm{Cl} 1.13-3.69)$ after 2 years of follow-up[103]. In this study, an increase of one unit in ASDAS corresponded to a 2.4 unit increase in SIJ SPARCC score. However, in patients with longer symptom duration (> 5 years), the correlation is weaker [104-106]. More data are needed to understand whether we can rely on MRI to monitor disease activity and treatment response in clinical practice.

Overall, disease activity monitoring using imaging is still not yet endorsed; clinical monitoring using the Ankylosing Spondylitis Disease Activity (ASDAS) as the preferred disease activity outcome measure, has been recommended by the 2017 task-force for the treat-to-target strategy of axSpA management [107].

\section{The misleading pitfalls and differential diagnosis of MRI imaging}

\section{Positive MRI by ASAS definition in non-SpA patients}

Several studies have shown that healthy subjects and conditions other than axSpA can present with BME in the SIJ on MRI fulfilling the ASAS criteria for a positive MRI. It is notable that the current ASAS criteria for axSpA diagnosis have unequivocal limitations which may lead spuriously to false-positive diagnosis. Further, it provides important insights into the specificity of BME lesions that have been much debated recently. Since a wide majority of patients present at the rheumatology clinic with low back pain, the challenge remains in recognizing specific MRI features to distinguish axSpA from common LBP and other diseases.

One study has shown that among 1020 patients with chronic back pain from a spine center, 21\% were falsely considered as having sacroiliitis according to the ASAS definition; of those $42 \%$ had only the minimum amount of BME required to fulfill the ASAS positive MRI [108]. This raises 
concerns about MRI specificity because subchondral BME may be induced by different causes including mechanical stress. Thus, the high prevalence of common LBP which may lead to a high number of falsely diagnosed axSpA when relying too much on MRI. In the study of Winter et al, the prevalence and extent of SIJ MRI inflammation were compared between axSpA and nonaxSpA subjects [10]. Although $91.5 \%$ of 47 axSpA patients had positive MRI for sacroiliitis according to the ASAS definition, $23.4 \%$ of the 47 healthy individuals without current or past back pain also had sacroiliitis with the same ASAS definition [10]. Similarly, $6.4 \%$ of 47 controls with chronic back pain, $12.5 \%$ of 24 runners, $57.1 \%$ of the 7 women with postpartum back pain, were also considered to have positive MRI by trained readers. However, high SPARCC scores $\geq 5$ were rarely found in healthy subjects, runners, or patients with chronic back pain. BME lesions were more frequently located in the anterior or posterior lower iliac bone in healthy persons whereas extensive BME lesions (homogeneous and unequivocal increase in signal $1 \mathrm{~cm}$ from the articular surface) were highly specific for axSpA [10]. A study by Weber et al. showed that $30-41 \%$ of young athletes met the ASAS definition of active sacroiliitis with BME in the SIJ affecting on average 3 to 4 SIJ quadrants mostly located in the posterior lower ilium and to a lesser extent in the anterior upper sacrum. However, bone erosion was absent [11]. Another study by Varkas et al evaluating mechanical stress on SIJ MRI has shown a high prevalence of BME lesions with a SPARCC score $\geq 1(40.9 \%)$ observed in 22 healthy active young military recruits without back pain symptoms [12]. Around 23\% of them displayed SIJ BME fulfilling the ASAS definition for sacroiliitis with a non-significant increase to $36.4 \%$ after 6 weeks of intensive physical training. These findings are consistent with the fact that SIJ BME seems to be mechanically induced or straininduced and this highlights again the importance of interpreting MRI by referring to the clinical history and background. This also highlights the serious problems in using the current quantitative definition of an ASAS positive MRI i.e. BME affecting $\geq 2$ SIJ quadrants, for diagnostic purposes [12].

\section{Which MRI lesions are specific to axSpA?}

Since MRI imaging has shown some lack in specificity when looking at only BME lesions, studies have been undertaken to find more specific MRI lesions and more appropriate thresholds. A retrospective study including 485 patients without rheumatologic diseases was interested in 
studying the specificity of fat metaplasia which is described as a typical structural lesion for sacroiliitis, and considered to be at an intermediate stage between inflammation and new bone formation[109]. In this study, periarticular fat metaplasia at the SIJ which was defined as adjacent to the joint and graded semi-quantitatively regarding its extent, appeared to be very prevalent and its frequency increased with age: it was detected in $51 \%$ of patients $<45$ years and $94.4 \%$ of patients $\geq 75$ years [109]. On the other hand, erosions were almost absent in age groups $\leq 45$ years (3\%) and also infrequent in patients $>45$ years, showing that erosions are a rather specific finding for axSpA [109].

In a recent prospective study, some MRI lesions seemed to be more specific for axSpA than others, contributing to differentiating axSpA patients from the other conditions included in the analysis: postpartum women, patients with disc herniation, cleaning staff, long-distance runners, and healthy men [110]. BME and fat metaplasia were present in all the groups studied with higher frequency and severity in axSpA patients followed by postpartum women with post-partum pain. At a higher cut-off, SPARCC BME $\geq 4$ was only observed in $\operatorname{axSpA}(61 \%)$ and women with postpartum pain (30\%) and none of the other groups (0\%): patients with disc herniation, cleaning staff, long-distance runners, and healthy men. In healthy men, the SPARCC BME score never exceeded 2 (SPARC BME $\leq 2$ ). Similarly, bone erosion was only seen in axSpA (61\%) and women with postpartum pain (9\%). At a higher cut-off $\geq 4$, erosion was almost exclusively seen in axSpA ( $34 \%$ in axSpA vs $2 \%$ in women, with postpartum pain) and erosions were always absent in the other groups (SPARCC erosion <1) [110]. Women with postpartum pain seem to be the primary diagnostic challenge; however, backfill lesion and ankylosis were highly specific of axSpA (occurred in $37 \%$ and $32 \%$ respectively) and were not seen in women with postpartum pain. The cut-off of SIJ BME and erosions were much lower in patients with other types of mechanical stress (ie, runners) or healthy men. Overall, while fat lesions and low levels of BME were seen in other conditions than axSpA, high levels of BME, erosions, backfill lesions, and ankylosis were highly specific for the diagnosis axSpA.

Recognizing SpA lesions and pitfalls is a crucial step to ascertain the diagnosis with careful regard to the clinical context, clinical signs, and biological tests. The results indicate a need for further defining the requirements for a positive sacroiliitis on MRI, with alternative approaches to 
overcome these limitations such as including the localization of the lesions in the SIJ [111], the combination of MRI inflammatory and structural lesions (e.g, BME with erosions), or better imaging techniques to detect highly specific lesions.

\section{Future potential imaging techniques}

\section{The magnetic resonance imaging VIBE technique}

It has been argued that BME lesions might be not specific enough for a reliable axSpA diagnosis, therefore, improving the visualization of specific lesions such as erosions might be of high relevance to this issue. An improvement of MRI sensitivity can be achieved with the volumetric interpolated breath-hold examination (VIBE-MRI) which is a fast three-dimensional MR technique employing a spoiled gradient-echo sequence. This MRI technique, the so-called 3DFLASH sequence with fat saturation, provides high contrast of the cartilage-bone interface with thinner slices leading to the detection of structural abnormalities at a higher resolution. In the SIMACT study, MRI-VIBE identified 16\% more patients with erosions compared to the standard T1W-MRI. MRI-VIBE detected even more erosions than with IdCT used as a reference standard while there was no difference in patients with no erosions in IdCT [112]. This increases the sensitivity for erosions with VIBE-MRI (Se: 0.95[0.82-0.99]) without a decrease in specificity (Spe: 0.93 [0.85-0.98]). MRI-VIBE was better and more reliable in the detection of SIJ erosions without increasing the number of false-positive findings [112]. Similarly, another study has shown that significantly more erosions in the SIJ were detected by MRI-VIBE compared to T1W-MRI and CT [113], ascertaining again that this new technique can be promising and further research is needed to better define its diagnostic performance and limitations.

\section{The Diffusion-weighted imaging}

Diffusion-weighted imaging (DWI) is an MRI method relying on the apparent diffusion coefficient $(A D C)$ which reflects the degree of movement of water molecules in tissue. In axSpA patients, BME reveals increased extracellular water in inflammatory regions and can yield a high signal on 
DWI with an increased ADC. In the DWI technique, the region of interest where inflammation is suspected has to be drawn and the spatial resolution is not optimal[114]. Also, this method is not superior to fluid-sensitive conventional MRI sequences in its diagnostic performance $[115,116]$. Images with DWI are prone to variability between 2 different examinations and between different MRI platforms [2]. This is caused by the ADC and internal reference standard variability: the internal reference standard itself may vary with the patient's age and sex, whereas, ADC values can be reduced by the presence of fat lesion which may impact the diffusion of water at BME regions. Despite its limitations in spatial resolution and ADC variability between readers and MRI units, DWI has been used as an objective tool for diagnostic purposes, improving the specificity of sacroiliitis detection and for monitoring of response to therapy in trials $[2,114]$, however, its additive value is still debated.

\section{The Dixon methods}

Other new MRI techniques, such as the modified Dixon and functional quantitative Gadoliniumchelate based contrast agents (GBCA)-enhanced dynamic MRI, are being explored in osteoarthritis and rheumatoid arthritis research [117]. Recently, the Dixon techniques have changed and improved. Now images of high-resolution high-contrast including water only and water-fat combined can be reconstructed in a single acquisition of nearly 2 minute-duration. The advantage of these techniques is that they are less subject to artifacts induced by field inhomogeneity in contrast to fat-suppressed sequences that can vary in mid and low field. They also have the ability to decrease technical variability and increase reproducibility between different MRI centers because of its adaptability independent of field strength [117]. A study including 107 patient with SpA has shown that there was no difference in diagnostic performance between the T2W Dixon and the standard protocol (T1W and fat-suppressed T2W sequence) with an area under the curve (AUC) of 0.73-0.75 versus 0.74-0.76 respectively and a higher interobserver agreements for BME and fat lesion on the Dixon sequence[118].

Therefore, integrating the Dixon methods into MRI protocols can be promising in the field of spondyloarthritis. 


\section{Positron emission tomography}

Positron emission tomography (PET) is a nuclear imaging technique that can be used as hybrid imaging when combined with CT or MRI for anatomical reference. Similarly to MRI, PET may be useful in the early diagnosis of axSpA since it may allow early detection of inflammatory changes even before structural damage occurs [119]. It can visualize and quantify disease activity at different targeted binding sites in the whole body (bone marrow, synovial tissue, ligament, and entheses) through the use of different specific tissue tracers.

\subsection{PET tracers}

Three PET tracers with different uptake mechanisms have been investigated in the SpA field. Two are inflammatory tracers: the ${ }^{18} \mathrm{~F}-\mathrm{FDG}\left({ }^{18} \mathrm{~F}\right.$-fluoro-deoxyglucose), a glucose analogue isotope that can visualize inflamed synovial tissue and the ${ }^{11} \mathrm{C}-\mathrm{PK} 11195$, that binds to macrophage receptors. The ${ }^{18}$ F-FDG seems to detect osteolytic lesions rather than osteoblastic lesions and may be less able to detect bone formation in axSpA with low or absent inflammation [120]. The third tracer, ${ }^{18} \mathrm{~F}$-Fluoride, is a bone tracer integrated into hydroxyapatite crystals and forming the mineral fluoro-apatite of the bone and seems to detect osteoblastic activity located mostly at active sites of bone formation in the axial skeleton [120].

\subsection{Diagnostic performance of ${ }^{18}$ F-Fluoride PET scan}

In a pilot study on 10 patients with AS, both inflammatory tracers ${ }^{18}$ F-FDG and ${ }^{11} \mathrm{C}-$ PK11195 did not show increased uptake on PET-CT scans whereas the ${ }^{18} \mathrm{~F}$-Fluoride bone tracer detected positive lesions in the spine and SIJ that matched with two-thirds of the MRI-BME lesions [120]. Thus, the ${ }^{18} \mathrm{~F}$-fluoride bone tracer seems to be more useful to evaluate disease activity in AS which is depicted by active bone formation rather than an inflammatory process [120].

Concerning inflammatory lesions in axSpA patients, a study showed a significant correlation between ${ }^{18}$ F-Fluoride PET uptake in the SIJ and inflammation on MRI (ICC [IC95] = 0.61[0.26; 0.82]; $p=0.001$ ), even if it was detected in only half of the patients [119]. Interestingly, ${ }^{18} \mathrm{~F}$ - fluoride PET scans recognized twice as many as having sacroiliitis compared to MRI and CT scans suggesting that ${ }^{18} \mathrm{~F}$-fluoride PET may be a more sensitive technique to detect early lesions not yet visible on 
MRI or CT scans [119]. Another study has shown a moderate correlation between ${ }^{18} \mathrm{~F}$-fluoride uptake on PET-MRI and BME in the SIJ (kappa=0.64) and a poor correlation in the spine (kappa=0.25) [121]. Overall, the correlation between osteoblastic activity on PET and BME is still controversial, especially in the spine $[119,122]$. Concerning structural lesions, no correlation was found between ${ }^{18} \mathrm{~F}$-fluoride PET and the presence of erosions, ankylosis, and sclerosis visible on the SIJ CT scans [119]. These findings suggest that ${ }^{18} \mathrm{~F}$-fluoride PET can probably detect early bone remodeling before structural lesions become visible on CT or MRI. On biopsy, these ${ }^{18} \mathrm{~F}$-fluoride PET-positive lesions corresponded to non-mineralized-osteoid tissue which was absent in PETnegative lesions [123].

On the other hand, although disease activity outcome measures such as BASDAI, ASDAS, and BASFI have shown a good correlation with the number of ${ }^{18} \mathrm{~F}$-fluoride high uptake lesions on PET [124], there is still limited evidence for the use of PET scans for monitoring of disease activity in active AS patients. Still, the hybrid PET technique seems to be a promising tool for the early diagnosis of axSpA.

\section{Bone scintigraphy and Single-Photon Emission Tomography}

Planar bone scintigraphy using a radionuclide tracer, the $99 \mathrm{~m}$-technetium methylene diphosphonate (99m-Tc MDP), has been extensively used to visualize sites with high bone turnover such as sacroiliitis but has shown to be of low diagnostic value in axSpA with poor correlation with MRI findings [15].

Compared to bone scintigraphy, 99m-Tc MDP single positron emission tomography (SPECT)/CT allows a more accurate anatomic localization in 3D and a more precise quantification of radionuclide tracer activity in the SIJ. A study has compared SPECT-CT to MRI for the diagnosis of sacroiliitis in 155 patients with SpA and has shown a sensitivity of $90 \%$ and specificity of $80 \%$ for SPECT-CT, with a diagnostic accuracy comparable to that of MRI [125]. More studies are awaited to delineate the role of $99 \mathrm{~m}-\mathrm{TC}$ MDP SPECT-CT imaging as an alternative imaging modality for SpA diagnosis in patient with a contraindication to MRI. 


\section{Immunoscintigraphy}

Immunoscintigraphy is a recent technique combining scintigraphy with the injection of a radiolabelled tracer, such as $99 \mathrm{~m}$-technetium labeled certolizumab pegol (99m-Tc CZP), which was evaluated in a pilot study [126]. A good correlation was found in 7 axSpA patients between the tracer uptake on immunoscintigraphy and BME on MRI within the same SIJ quadrant. Also, there was excellent agreement between deep BME lesions on SIJ-MRI and clear tracer uptake (score 2 ) assessed by SPECT ( $r$ spearman $=0.986(p<0.00)$ and $0.956(p<0.00)$ for left and right SIJ respectively) [126]. It has not been fully elucidated whether this immunoscintigraphic procedure using monoclonal anti-cytokine antibodies, can possibly be used to determine the underlying cytokine that drive the inflammatory process observed in BME lesions. The present observations with CZP provide insight into the possibility of a future individualized biologic treatment approach.

\section{Whole body-MRI}

Whole-body magnetic resonance imaging (WBMRI) can assess simultaneously both axial and peripheral joints/entheses in the same examination. Validated scoring methods are now developed to quantify the overall inflammatory load in SpA patients [127]. Although correlations with clinical evaluations have been poor[128,129], WBMRI showed a significant decline of inflammation following TNFi treatment $[130,131]$ in parallel with a significant decrease in disease activity outcome measures in SpA [132]. While its prognostic value is still unclear, WBMRI is a promising tool for SpA evaluation and monitoring.

\section{Dual-Energy Computed Tomography}

Dual-Energy Computed Tomography (DECT) is a new technique using dual-source spiral CT scanners with the same radiation dose as standard CT and involves the acquisition of images 
simultaneously at 2 energy levels (classically, tube voltages at 80 and $140 \mathrm{kV}$ ) corresponding to elements with a high atomic number or, as most of the human body tissues, to low atomic numbers. DECT has been used in gout (for the evaluation of urate deposition), calcium pyrophosphate deposition disease (CPPD), rheumatoid arthritis, and psoriatic arthritis[114]. Based on the x-ray absorption values, DECT with the virtual non-calcium (VNCa) technique, can visualize and quantify on a color-coded map the different components of bone marrow: yellow bone marrow/fat in blue color, BME/ water in green color. In a study on 47 SpA patients, DECT has been used to detect sacroiliitis/BME in the SIJ with good sensitivity (87\% and 93\% for readers 1 and 2 ) and specificity (94\% and 91\% for readers 1 and 2); MRI was the reference standard for BME [133]. Thus, DECT may be an alternative emerging technique for BME detection especially in SpA patients with contraindication to MRI. 


\section{Summary}

Imaging and especially MRI is a key asset for the early recognition of clinically suspected axSpA as well as for monitoring, prognosticating patients with confirmed axSpA. While CT performs better for structural changes, MRI is the best imaging tool to visualize inflammation at the earliest disease stages. A consensus-based update of standardized definitions for MRI lesions of the SIJ were recently updated by the ASAS MRI working group to improve agreement between physicians and enhance research initiatives. However, because of the mechanical stress on the pelvic area (i.g. post-partum women), limitations and pitfalls of the different imaging modalities mostly need to be considered when diagnosing axSpA. Further studies are awaited to better define specific MRI lesions and cut-offs that could be integrated in a new ASAS definition of a positive MRI in SpA. Also, improving imaging performance and incorporating the newest imaging modalities into the clinical practice is a real challenge.

\section{Practice points}

- $\mathrm{MRI}$ is the best imaging modality to diagnose axSpA at the earliest stages of the disease.

- Recognizing limitation and pitfalls of MRI imaging is a crucial step to ascertain the diagnosis with careful regard to the clinical context, clinical signs, and biological tests.

- Athletes, women with post-partum pain, patients with chronic back pain and even healthy subjects can present BME in the SIJ on MRI fulfilling falsely the ASAS criteria for a positive MRI.

- Localization of the lesions in the SIJ, higher cut-off for BME lesions, and detection of highly specific MRI lesions constitute alternative approaches to overcome these limitations for axSpA diagnosis. 


\section{Research agenda}

- Future perspectives are directed toward more advanced MRI techniques such as VIBE-MRI technique or the Dixon methods that improve imaging performances with a better visualization of structural damage, less technical variability and more reproducibility between institutions.

- While more studies are awaited to prove their diagnostic utility, newest imaging modalities such as the 18F-Fluoride PET scan, DECT, 99m-Tc SPECT-CT, whole body-MRI may be promising tools in the field of spondyloarthritis possibly for further defining a positive sacroiliitis and for disease monitoring on treatment.

- Immunoscintigraphy using monoclonal anti-cytokine antibodies, such as certolizumab pegol, may potentially delineate a future individualized biologic treatment approach.

- Improving imaging performance and integrating the newest imaging modalities into clinical practice are now the current challenge.

\section{Conflict of interest/ disclosure:}

Walter P. Maksymowych is Chief Medical Officer of CARE Arthritis Limited.

$K A, X B, N Z$ : no conflict of interest.

\section{Funding:}

No funding for this study 


\section{Tables and Figures}

Figure 1. Active inflammatory lesions on MRI images of the sacroiliac joints in patients with axial spondyloarthritis, as defined by the ASAS MRI working group [14,23]. All images have been acquired in the semicoronal orientation. ASAS, Assessment of SpondyloArthritis international Society; CRP, C-reactive protein; NSAID, nonsteroidal antiinflammatory drug; STIR, short tau inversion recovery; T1W, T1-weighted. Images obtained from https://www.carearthritis.com/mriportal/mriopencourse/ with permission. 


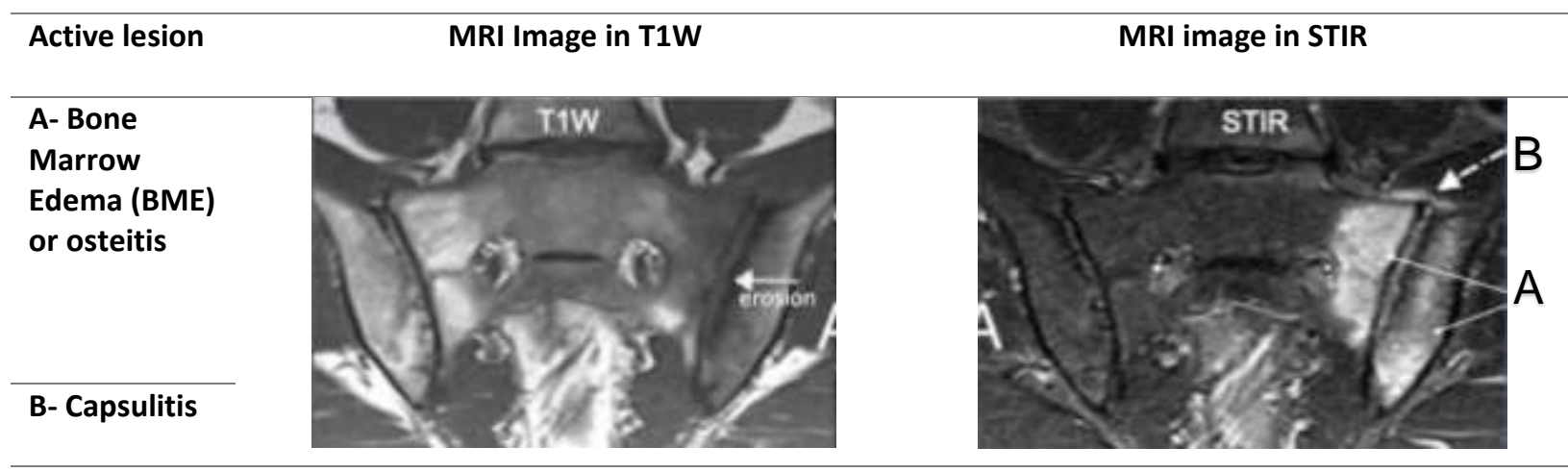

A- MRI scans of a 42-year-old man with a 1-year history of inflammatory back pain, a single episode of acute anterior uveitis, HLA-B27 positivity and a CRP level of $67.5 \mathrm{mg} / \mathrm{L}$. Extensive BME in the left iliac and sacral subchondral bone marrow is depicted as bright signal on the STIR MRI scan meeting the ASAS definition of a positive MRI.

B- Bright signal in the anterosuperior joint capsule on the STIR scan meeting the ASAS definition of capsulitis.

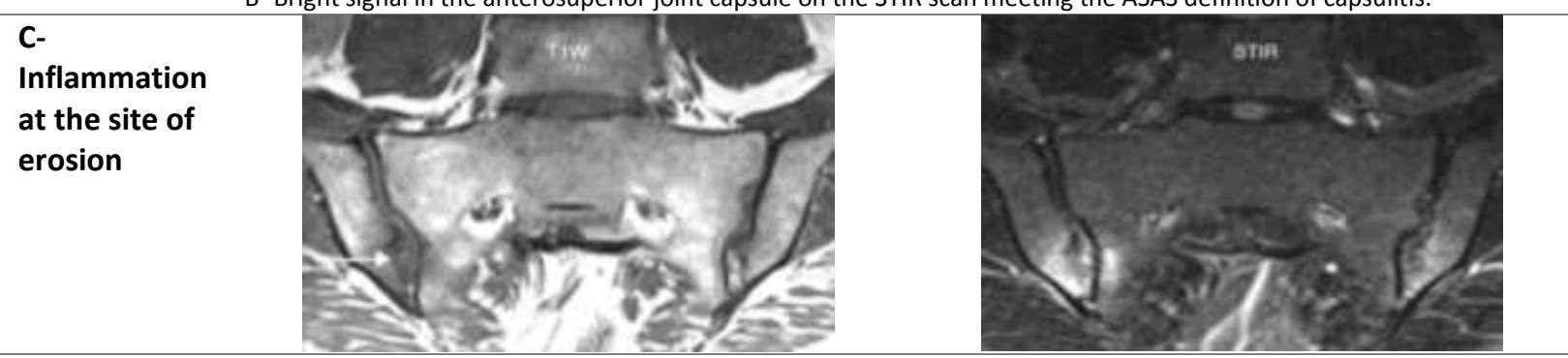

MRI scans of a 35-year-old man with a 5-year history of inflammatory back pain, lack of response to NSAID therapy, HLAB27 positivity and a CRP level of $6.8 \mathrm{mg} / \mathrm{L}$. The arrow on the T1W scan points to erosion of the right iliac bone. There is bright signal in the cavity of the erosion on the STIR scan, indicating that there is inflammation within the erosion cavity meeting the ASAS definition.

\section{D- Enthesitis}
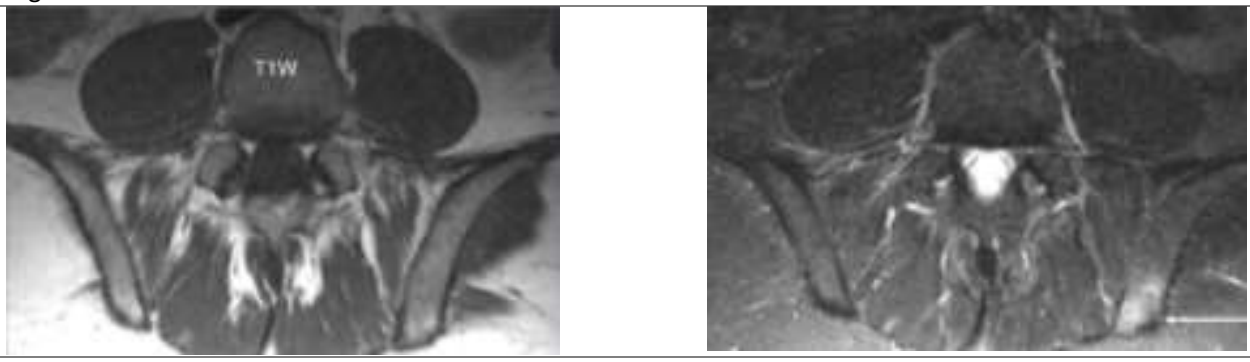

The arrow on the STIR scan points to bright signal in the bone marrow of the left iliac bone several slices posterior to the sacroiliac joint. This meets the ASAS definition of enthesitis.

E- Joint space
fluid
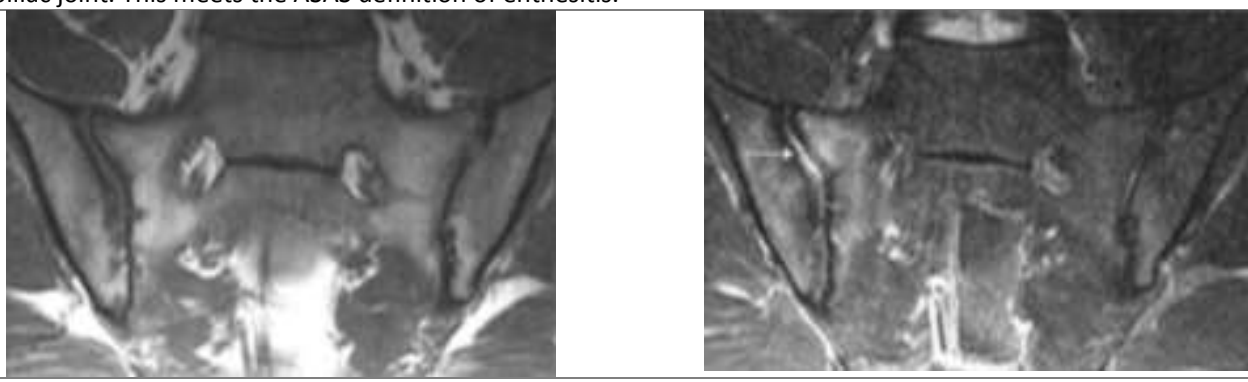

MRI scan of a 33-year-old man with a 2-year history of inflammatory back pain, HLA-B27 positive and a CRP level of 18.6 $\mathrm{mg} / \mathrm{L}$. The arrow on the STIR scan points to bright signal, with intensity comparable to vascular signal, in the right sacroiliac joint space. This meets the ASAS definition of joint fluid. 
Figure 2. Structural lesions on MRI images of the sacroiliac joints in patients with axial spondyloarthritis, as defined by the ASAS MRI working group [14,23].. All images have been acquired in the semicoronal orientation. ASAS, Assessment of SpondyloArthritis international Society; CRP, C-reactive protein; NSAID, nonsteroidal antiinflammatory drug; STIR, short tau inversion recovery; T1W, T1-weighted. Images obtained from https://www.carearthritis.com/mriportal/mriopencourse/ with permission. 


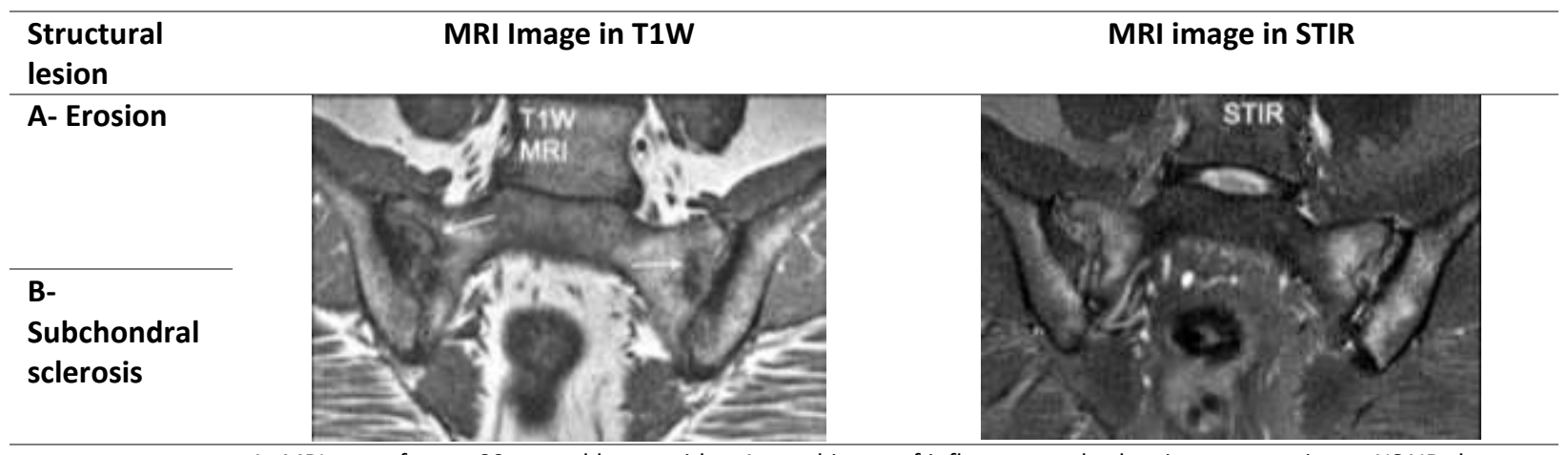

A- MRI scans from a 39-year-old man with a 4-year history of inflammatory back pain unresponsive to NSAID therapy, HLA-B27 positivity and a CRP level of $18.8 \mathrm{mg} / \mathrm{L}$. The arrows on the T1W scan point to large sacral erosions with loss of cortical bone and adjacent marrow matrix meeting the ASAS definition for erosion.

B- There is dark signal in both iliac bones on both MRI sequences meeting the ASAS definition for bone sclerosis.

C- Fat lesion
or fat
metaplasia
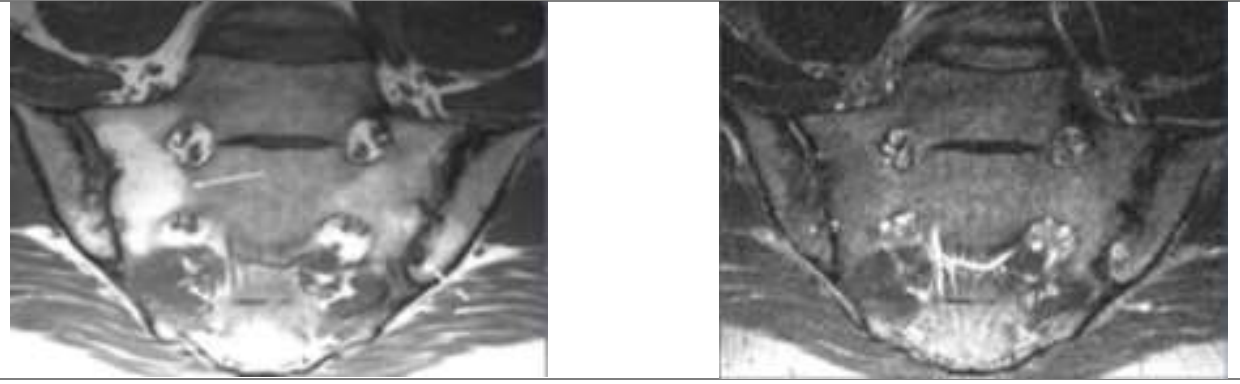

MRI scan of a 32-yearold man with a 3-year history of inflammatory back pain, Crohn's colitis controlled with TNF inhibitor therapy, HLA-B27 negativity and a CRP level of $3.5 \mathrm{mg} / \mathrm{L}$. The arrow points to a region of homogeneously increased signal in the right sacral bone marrow on the T1W scan that has a distinct border and is adjacent to subchondral bone and erosion of the right sacral cortex. This appearance meets the ASAS definition for fat metaplasia related to SpA. There are smaller areas of fat metaplasia in both lower iliac bones adjacent to areas of erosion, especially the left iliac cortex (arrow).

D- Fat
metaplasia in
the erosion
cavity,
known as
"backfill"
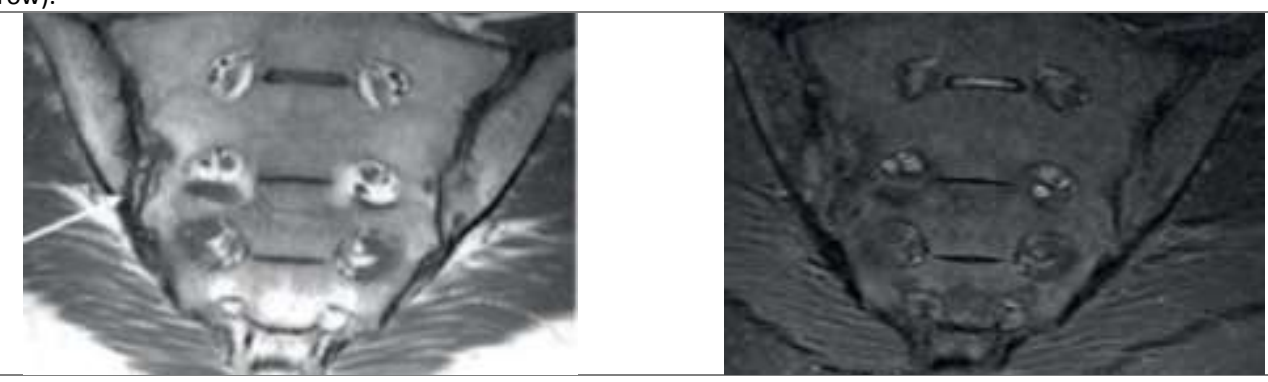

MRI images of the sacroiliac joints of a patient after anti-TNF therapy. Bright signal in the joint space (arrow) at the site of previous erosion bordered laterally by an irregular dark band. This composite appearance is typical of backfill.

\section{E- Non- bridging bone bud}

F- Ankylosis
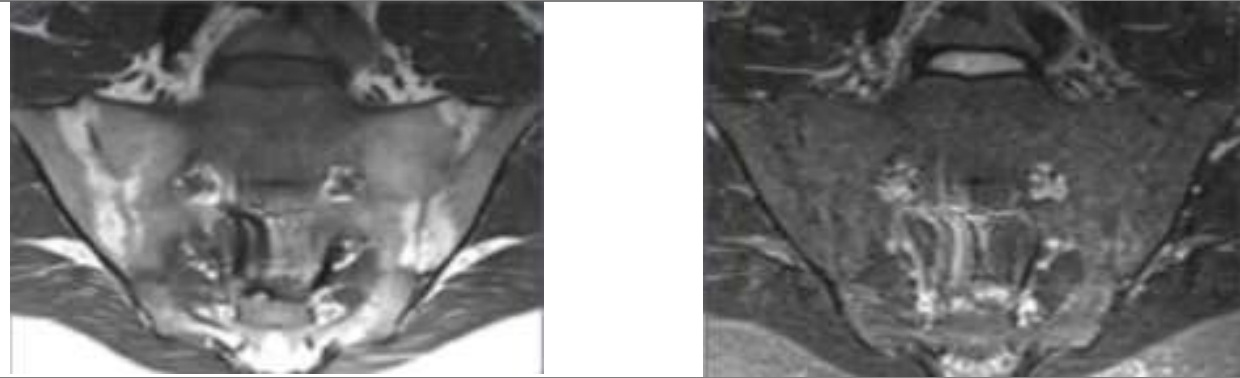

MRI scans of a 54-year-old woman with a 23-year history of inflammatory back pain responsive to NSAID therapy, HLAB27 positivity and a CRP level of $4.2 \mathrm{mg} / \mathrm{L}$. The T1W scan demonstrates several regions of both sacroiliac joints where there is continuity of bright marrow signal from ilium to sacrum across the joint space meeting the ASAS definition for ankylosis. 
Figure 3. Characteristic lesions in the spine of patients with axial spondyloarthritis as depicted by MRI. Images obtained from https://www.carearthritis.com/mriportal/mriopencourse/ with permission.

\section{Spine lesions in axial spondyloarthritis depicted by MRI Bone Marrow Edema \\ Multiple foci of inflammation are identified in the lateral aspects of 6 consecutive thoracic vertebrae (T7-T12). At $\mathrm{T} 7 / 8$, intense edema is present in the facet processes. At all six levels in this case, some or all of the edema is due to costovertebral inflammation. \\ Faint anterior corner inflammatory lesions are present at T11 (inferior), T12 (superior and inferior) and L4 (superior).}

\section{Fat infiltration}

Multiple focal fat lesions of bone marrow are present at many vertebral body corners, anteriorly and posteriorly.

\section{Anterior ankylosis}

T11/12 subtle ankylosis is present with bright signal in bridging bony spurs - at the threshold for detection.

\section{Spine Erosion}

An anterior Corner bone erosion (COBE) is present at the $\mathrm{L} 1$ inferior endplate on the T1 image. The STIR image shows increased signal indicating active inflammation at this corner.

There is a large central non-corner bone erosion (NOBE) at the L2 inferior endplate [on the STIR image a non-corner inflammatory lesion with a dimorphic appearance is seen], at the L3 inferior endplate, L5 superior endplate and the L5 inferior endplate.

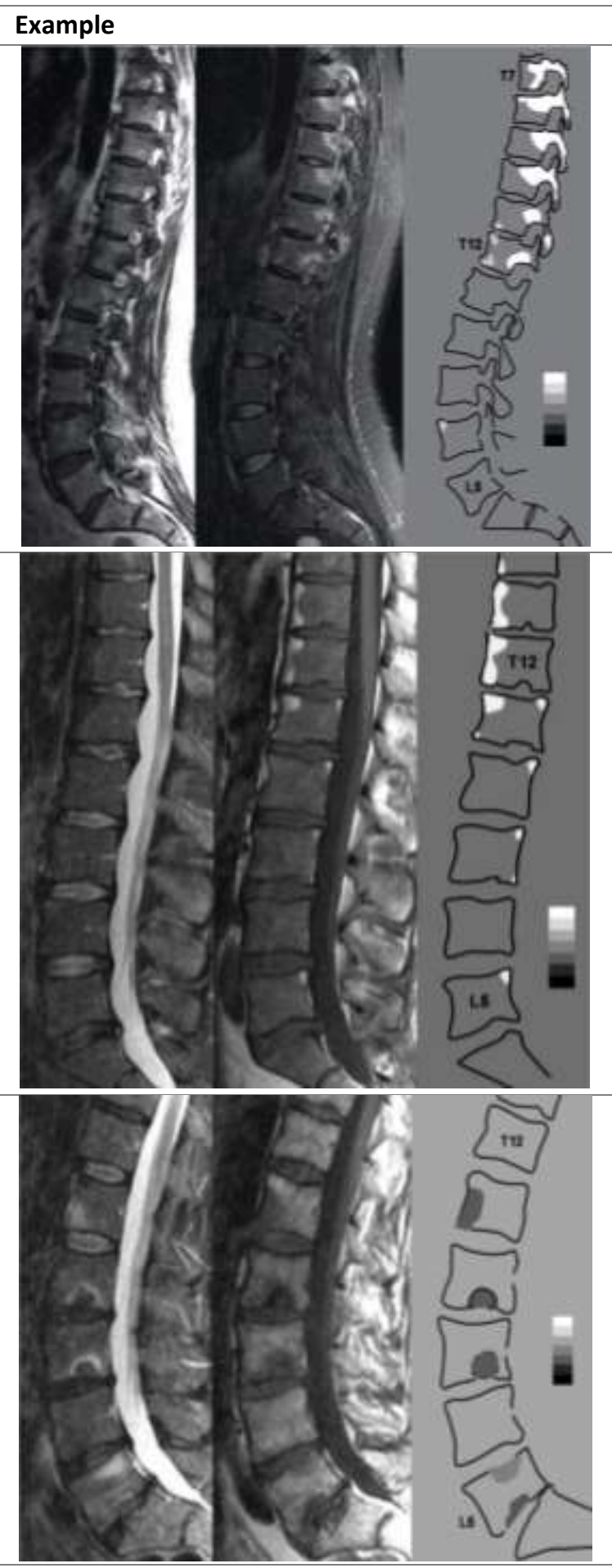


Table 1. Overview of the imaging techniques used in the sacro-iliac and spine in axial spondyloarthritis, with comparison of their advantages (pros) and limitations (cons)

\begin{tabular}{|c|c|c|c|c|c|}
\hline & Pros & Cons & Radiation & Cost & Availability \\
\hline $\begin{array}{l}\text { Conventional } \\
\text { radiography }\end{array}$ & $\begin{array}{l}\text { Current gold standard for } \\
\text { the assessment and } \\
\text { quantification of structural } \\
\text { lesions } \\
\text { Prognostic value for disease } \\
\text { progression }\end{array}$ & $\begin{array}{l}\text { Low reliability, sensitivity } \\
\text { and specificity } \\
\text { Inflammatory lesions not } \\
\text { visualized } \\
\text { Thoracic spine not } \\
\text { visualized } \\
\text { Lateral and posterior } \\
\text { elements of spine not } \\
\text { visualized }\end{array}$ & + & + & +++ \\
\hline $\begin{array}{l}\text { Low dose } \\
\text { computed } \\
\text { tomography }\end{array}$ & $\begin{array}{l}\text { Imaging of the whole spine } \\
\text { with visualization of the } \\
\text { thoracic spine, and lateral } \\
\text { and posterior elements }\end{array}$ & $\begin{array}{l}\text { Inflammatory lesions not } \\
\text { visualized } \\
\text { Lack of data regarding } \\
\text { sensitivity and specificity } \\
\text { for structural lesions } \\
\text { Lack of data on sensitivity } \\
\text { to changel }\end{array}$ & + & ++ & +++ \\
\hline $\begin{array}{l}\text { Magnetic } \\
\text { resonance } \\
\text { imaging }\end{array}$ & $\begin{array}{l}\text { Best method for detecting } \\
\text { inflammatory lesions } \\
\text { Differential diagnosis during } \\
\text { spinal pain flares } \\
\text { Selection of responders to } \\
\text { therapy } \\
\text { Prediction of structural } \\
\text { progression based on fat } \\
\text { metaplasia }\end{array}$ & $\begin{array}{l}\text { Specificity } \\
\text { Minimal added value of } \\
\text { spinal MRI over SIJ MRI for } \\
\text { axSpA diagnosis }\end{array}$ & - & +++ & $\begin{array}{c}\quad++ \\
\text { (depending } \\
\text { on regions } \\
\text { and settings) }\end{array}$ \\
\hline
\end{tabular}




\section{References}

[1] Aouad K, De Craemer A-S, Carron P. Can Imaging Be a Proxy for Remission in Axial Spondyloarthritis? Rheum Dis Clin North Am 2020;46:311-25.

[2] Maksymowych WP. The role of imaging in the diagnosis and management of axial spondyloarthritis. Nat Rev Rheumatol 2019;15:657-72.

[3] Baraliakos X, Maksymowych WP. Imaging in the diagnosis and management of axial spondyloarthritis. Best Pract Res Clin Rheumatol 2016;30:608-23.

[4] Aouad K, Ziade N, Baraliakos X. Structural progression in axial spondyloarthritis. Jt Bone Spine Rev Rhum 2019.

[5] Rudwaleit M, Khan MA, Sieper J. The challenge of diagnosis and classification in early ankylosing spondylitis: do we need new criteria? Arthritis Rheum 2005;52:1000-8.

[6] Lambert RGW, Bakker PAC, van der Heijde D, Weber U, Rudwaleit M, Hermann KG, et al. Defining active sacroiliitis on MRI for classification of axial spondyloarthritis: update by the ASAS MRI working group. Ann Rheum Dis 2016;75:1958-63.

[7] Rudwaleit M, van der Heijde D, Landewé R, Listing J, Akkoc N, Brandt J, et al. The development of Assessment of SpondyloArthritis international Society classification criteria for axial spondyloarthritis (part II): validation and final selection. Ann Rheum Dis 2009;68:777-83.

[8] Maksymowych WP, Wichuk S, Dougados $M$, Jones $H$, Szumski A, Bukowski JF, et al. MRI evidence of structural changes in the sacroiliac joints of patients with non-radiographic axial spondyloarthritis even in the absence of MRI inflammation. Arthritis Res Ther 2017;19:126.

[9] Lukas C, Cyteval C, Dougados M, Weber U. MRI for diagnosis of axial spondyloarthritis: major advance with critical limitations "Not everything that glisters is gold (standard)." RMD Open 2018;4:e000586.

[10] de Winter J, de Hooge $M$, van de Sande $M$, de Jong $H$, van Hoeven $L$, de Koning $A$, et al. Magnetic Resonance Imaging of the Sacroiliac Joints Indicating Sacroiliitis According to the Assessment of SpondyloArthritis international Society Definition in Healthy Individuals, Runners, and Women With Postpartum Back Pain. Arthritis Rheumatol Hoboken NJ 2018;70:1042-8.

[11] Weber U, Jurik AG, Zejden A, Larsen E, Jørgensen SH, Rufibach K, et al. Frequency and Anatomic Distribution of Magnetic Resonance Imaging Features in the Sacroiliac Joints of Young Athletes: Exploring "Background Noise" Toward a Data-Driven Definition of Sacroiliitis in Early Spondyloarthritis. Arthritis Rheumatol Hoboken NJ 2018;70:736-45. 
[12] Varkas G, de Hooge M, Renson T, De Mits S, Carron P, Jacques P, et al. Effect of mechanical stress on magnetic resonance imaging of the sacroiliac joints: assessment of military recruits by magnetic resonance imaging study. Rheumatol Oxf Engl 2018;57:508-13.

[13] Mandl P, Navarro-Compán V, Terslev L, Aegerter $P$, van der Heijde D, D'Agostino MA, et al. EULAR recommendations for the use of imaging in the diagnosis and management of spondyloarthritis in clinical practice. Ann Rheum Dis 2015;74:1327-39.

[14] Maksymowych WP, Lambert RG, Østergaard M, Pedersen SJ, Machado PM, Weber U, et al. MRI lesions in the sacroiliac joints of patients with spondyloarthritis: an update of definitions and validation by the ASAS MRI working group. Ann Rheum Dis 2019;78:1550-8.

[15] De Hooge M. The Future of Imaging in Axial Spondyloarthritis. Rheum Dis Clin North Am 2020;46:297-309.

[16] van der Linden S, Valkenburg HA, Cats A. Evaluation of diagnostic criteria for ankylosing spondylitis. A proposal for modification of the New York criteria. Arthritis Rheum 1984;27:361-8.

[17] Expert Panel on Musculoskeletal Imaging:, Bernard SA, Kransdorf MJ, Beaman FD, Adler RS, Amini B, et al. ACR Appropriateness Criteria ${ }^{\circledR}$ Chronic Back Pain Suspected SacroiliitisSpondyloarthropathy. J Am Coll Radiol JACR 2017;14:S62-70.

[18] Sieper J, Rudwaleit M, Baraliakos X, Brandt J, Braun J, Burgos-Vargas R, et al. The Assessment of SpondyloArthritis international Society (ASAS) handbook: a guide to assess spondyloarthritis. Ann Rheum Dis 2009;68:ii1-44. https://doi.org/10.1136/ard.2008.104018.

[19] Battistone MJ, Manaster BJ, Reda DJ, Clegg DO. Radiographic diagnosis of sacroiliitis--are sacroiliac views really better? J Rheumatol 1998;25:2395-401.

[20] Weber U, Baraliakos X. Imaging in axial spondyloarthritis: Changing concepts and thresholds. Best Pract Res Clin Rheumatol 2018;32:342-56.

[21] Tan S, Ward MM. Computed tomography in axial spondyloarthritis. Curr Opin Rheumatol 2018;30:334-9.

[22] Melchior J, Azraq Y, Chary-Valckenaere I, Rat A-C, Reignac M, Texeira P, et al. Radiography, abdominal CT and MRI compared with sacroiliac joint CT in diagnosis of structural sacroiliitis. Eur J Radiol 2017;95:169-76.

[23] Rudwaleit M, Jurik AG, Hermann K-GA, Landewé R, Heijde D van der, Baraliakos X, et al. Defining active sacroiliitis on magnetic resonance imaging (MRI) for classification of axial spondyloarthritis: a consensual approach by the ASAS/OMERACT MRI group. Ann Rheum Dis 2009;68:1520-7. 
[24] Maksymowych WP, Inman RD, Salonen D, Dhillon SS, Williams M, Stone M, et al. Spondyloarthritis research Consortium of Canada magnetic resonance imaging index for assessment of sacroiliac joint inflammation in ankylosing spondylitis. Arthritis Rheum 2005;53:703-9.

[25] Sudoł-Szopińska I, Jurik AG, Eshed I, Lennart J, Grainger A, Østergaard M, et al. Recommendations of the ESSR Arthritis Subcommittee for the Use of Magnetic Resonance Imaging in Musculoskeletal Rheumatic Diseases. Semin Musculoskelet Radiol 2015;19:396411.

[26] Greese J, Diekhoff T, Sieper J, Schwenke C, Makowski MR, Poddubnyy D, et al. Detection of Sacroiliitis by Short-tau Inversion Recovery and T2-weighted Turbo Spin Echo Sequences: Results from the SIMACT Study. J Rheumatol 2019;46:376-83.

[27] Jones A, Bray TJP, Mandl P, Hall-Craggs MA, Marzo-Ortega H, Machado PM. Performance of magnetic resonance imaging in the diagnosis of axial spondyloarthritis: a systematic literature review. Rheumatol Oxf Engl 2019;58:1955-65.

[28] Laloo F, Herregods N, Varkas G, Jaremko JL, Baraliakos X, Elewaut D, et al. MR signal in the sacroiliac joint space in spondyloarthritis: a new sign. Eur Radiol 2017;27:2024-30.

[29] Schwartzman M, Maksymowych WP. Is There a Role for MRI to Establish Treatment Indications and Effectively Monitor Response in Patients with Axial Spondyloarthritis? Rheum Dis Clin North Am 2019;45:341-58.

[30] Dougados M, Sepriano A, Molto A, Lunteren M van, Ramiro S, Hooge M de, et al. Sacroiliac radiographic progression in recent onset axial spondyloarthritis: the 5-year data of the DESIR cohort. Ann Rheum Dis 2017;76:1823-8.

[31] Wang DM, Lin L, Peng JH, Gong Y, Hou ZD, Chen SB, et al. Pannus inflammation in sacroiliitis following immune pathological injury and radiological structural damage: a study of 193 patients with spondyloarthritis. Arthritis Res Ther 2018;20:120.

[32] Baraliakos X, Listing J, Rudwaleit M, Haibel H, Brandt J, Sieper J, et al. Progression of radiographic damage in patients with ankylosing spondylitis: defining the central role of syndesmophytes. Ann Rheum Dis 2007;66:910-5.

[33] Ramiro S, Stolwijk C, van Tubergen A, van der Heijde D, Dougados M, van den Bosch F, et al. Evolution of radiographic damage in ankylosing spondylitis: a 12 year prospective followup of the OASIS study. Ann Rheum Dis 2015;74:52-9.

[34] Gran JT, Skomsvoll JF. The outcome of ankylosing spondylitis: a study of 100 patients. $\mathrm{Br}$ J Rheumatol 1997;36:766-71.

[35] Gaucher AA, Péré PG, Gillet PM. From ankylosing spondylitis to Forestier's disease: ossifying enthesopathy, a unifying concept. J Rheumatol 1990;17:854-6. 
[36] Ramiro S, van der Heijde D, Sepriano A, van Lunteren M, Moltó A, Feydy A, et al. Spinal radiographic progression in early axial Spondyloarthritis: Five-year results from the DESIR cohort. Arthritis Care Res 2018.

[37] Averns HL, Oxtoby J, Taylor HG, Jones PW, Dziedzic K, Dawes PT. Radiological outcome in ankylosing spondylitis: use of the Stoke Ankylosing Spondylitis Spine Score (SASSS). Br J Rheumatol 1996;35:373-6.

[38] MacKay K, Mack C, Brophy S, Calin A. The Bath Ankylosing Spondylitis Radiology Index (BASRI): a new, validated approach to disease assessment. Arthritis Rheum 1998;41:226370.

[39] Wanders AJB, Landewé RBM, Spoorenberg A, Dougados $M$, van der Linden S, Mielants $H$, et al. What is the most appropriate radiologic scoring method for ankylosing spondylitis? A comparison of the available methods based on the Outcome Measures in Rheumatology Clinical Trials filter. Arthritis Rheum 2004;50:2622-32.

[40] Creemers MCW, Franssen MJ a. M, van't Hof MA, Gribnau FWJ, van de Putte LBA, van Riel PLCM. Assessment of outcome in ankylosing spondylitis: an extended radiographic scoring system. Ann Rheum Dis 2005;64:127-9.

[41] Tan S, Wang R, Ward MM. Syndesmophyte growth in ankylosing spondylitis. Curr Opin Rheumatol 2015;27:326-32.

[42] van der Heijde D, Braun J, Deodhar A, Baraliakos X, Landewé R, Richards HB, et al. Modified stoke ankylosing spondylitis spinal score as an outcome measure to assess the impact of treatment on structural progression in ankylosing spondylitis. Rheumatol Oxf Engl 2019;58:388-400.

[43] Maksymowych WP, Learch T, Lambert RG, Ward M, Haroon N, Inman R, et al. Development and validation of the spondyloarthritis radiography module for calibration of readers using the modified Stoke Ankylosing Spondylitis Spine Score. Arthritis Care Res 2014;66:55-62.

[44] Baraliakos X, Landewe R, Hermann K, Listing J, Golder W, Brandt J, et al. Inflammation in ankylosing spondylitis: a systematic description of the extent and frequency of acute spinal changes using magnetic resonance imaging. Ann Rheum Dis 2005;64:730-4.

[45] Maas F, Arends S, Brouwer E, Bootsma H, Bos R, Wink FR, et al. Incorporating assessment of the cervical facet joints in the modified Stoke ankylosing spondylitis spine score is of additional value in the evaluation of spinal radiographic outcome in ankylosing spondylitis. Arthritis Res Ther 2017;19.

[46] Koning A de, Bruin F de, Berg R van den, Ramiro S, Baraliakos X, Braun J, et al. Low-dose $\mathrm{CT}$ detects more progression of bone formation in comparison to conventional radiography 
in patients with ankylosing spondylitis: results from the SIAS cohort. Ann Rheum Dis 2018;77:293-9.

[47] Braun J, Baraliakos X, Golder W, Hermann K-G, Listing J, Brandt J, et al. Analysing chronic spinal changes in ankylosing spondylitis: a systematic comparison of conventional $x$ rays with magnetic resonance imaging using established and new scoring systems. Ann Rheum Dis 2004;63:1046-55.

[48] Hermann K-GA, Baraliakos X, van der Heijde DMFM, Jurik A-G, Landewé R, Marzo-Ortega $H$, et al. Descriptions of spinal MRI lesions and definition of a positive MRI of the spine in axial spondyloarthritis: a consensual approach by the ASAS/OMERACT MRI study group. Ann Rheum Dis 2012;71:1278-88.

[49] Maksymowych WP, Crowther SM, Dhillon SS, Conner-Spady B, Lambert RGW. Systematic assessment of inflammation by magnetic resonance imaging in the posterior elements of the spine in ankylosing spondylitis. Arthritis Care Res 2010;62:4-10.

[50] Bochkova AG, Levshakova AV, Bunchuk NV, Braun J. Spinal inflammation lesions as detected by magnetic resonance imaging in patients with early ankylosing spondylitis are more often observed in posterior structures of the spine. Rheumatol Oxf Engl 2010;49:74955.

[51] Rudwaleit M, Schwarzlose S, Hilgert ES, Listing J, Braun J, Sieper J. MRI in predicting a major clinical response to anti-tumour necrosis factor treatment in ankylosing spondylitis. Ann Rheum Dis 2008;67:1276-81.

[52] Maksymowych WP, Wichuk S, Chiowchanwisawakit P, Lambert RG, Pedersen SJ. Development and preliminary validation of the spondyloarthritis research consortium of Canada magnetic resonance imaging sacroiliac joint structural score. J Rheumatol 2015;42:79-86.

[53] Weber U, Hodler J, Kubik RA, Rufibach K, Lambert RGW, Kissling RO, et al. Sensitivity and specificity of spinal inflammatory lesions assessed by whole-body magnetic resonance imaging in patients with ankylosing spondylitis or recent-onset inflammatory back pain. Arthritis Rheum 2009;61:900-8.

[54] Rennie WJ, Dhillon SS, Conner-Spady B, Maksymowych WP, Lambert RGW. Magnetic resonance imaging assessment of spinal inflammation in ankylosing spondylitis: standard clinical protocols may omit inflammatory lesions in thoracic vertebrae. Arthritis Rheum 2009;61:1187-93.

[55] Chiowchanwisawakit P, Lambert RGW, Conner-Spady B, Maksymowych WP. Focal fat lesions at vertebral corners on magnetic resonance imaging predict the development of new syndesmophytes in ankylosing spondylitis. Arthritis Rheum 2011;63:2215-25. 
[56] Pedersen SJ, Chiowchanwisawakit P, Lambert RGW, Østergaard M, Maksymowych WP. Resolution of inflammation following treatment of ankylosing spondylitis is associated with new bone formation. J Rheumatol 2011;38:1349-54.

[57] Baraliakos X, Heldmann F, Callhoff J, Listing J, Appelboom T, Brandt J, et al. Which spinal lesions are associated with new bone formation in patients with ankylosing spondylitis treated with anti-TNF agents? A long-term observational study using MRI and conventional radiography. Ann Rheum Dis 2014;73:1819-25.

[58] Machado PM, Baraliakos X, van der Heijde D, Braun J, Landewé R. MRI vertebral corner inflammation followed by fat deposition is the strongest contributor to the development of new bone at the same vertebral corner: a multilevel longitudinal analysis in patients with ankylosing spondylitis. Ann Rheum Dis 2016;75:1486-93.

[59] Baraliakos X, Boehm H, Bahrami R, Samir A, Schett G, Luber M, et al. What constitutes the fat signal detected by MRI in the spine of patients with ankylosing spondylitis? A prospective study based on biopsies obtained during planned spinal osteotomy to correct hyperkyphosis or spinal stenosis. Ann Rheum Dis 2019;78:1220-5.

[60] de Hooge M, van den Berg R, Navarro-Compán V, Reijnierse M, van Gaalen F, Fagerli K, et al. Patients with chronic back pain of short duration from the SPACE cohort: which MRI structural lesions in the sacroiliac joints and inflammatory and structural lesions in the spine are most specific for axial spondyloarthritis? Ann Rheum Dis 2016;75:1308-14.

[61] Bennett AN, Rehman A, Hensor EMA, Marzo-Ortega H, Emery P, McGonagle D. Evaluation of the diagnostic utility of spinal magnetic resonance imaging in axial spondylarthritis. Arthritis Rheum 2009;60:1331-41.

[62] Weber U, Zhao Z, Rufibach K, Zubler V, Lambert RGW, Chan SM, et al. Diagnostic utility of candidate definitions for demonstrating axial spondyloarthritis on magnetic resonance imaging of the spine. Arthritis Rheumatol Hoboken NJ 2015;67:924-33.

[63] Haibel H, Rudwaleit M, Brandt HC, Grozdanovic Z, Listing J, Kupper H, et al. Adalimumab reduces spinal symptoms in active ankylosing spondylitis: clinical and magnetic resonance imaging results of a fifty-two-week open-label trial. Arthritis Rheum 2006;54:678-81.

[64] Maksymowych WP, Inman RD, Salonen D, Dhillon SS, Krishnananthan R, Stone M, et al. Spondyloarthritis Research Consortium of Canada magnetic resonance imaging index for assessment of spinal inflammation in ankylosing spondylitis. Arthritis Rheum 2005;53:502-9.

[65] van der Heijde D, Baraliakos X, Gensler LS, Maksymowych WP, Tseluyko V, Nadashkevich $O$, et al. Efficacy and safety of filgotinib, a selective Janus kinase 1 inhibitor, in patients with active ankylosing spondylitis (TORTUGA): results from a randomised, placebo-controlled, phase 2 trial. Lancet Lond Engl 2018;392:2378-87. 
[66] van der Heijde D, Cheng-Chung Wei J, Dougados M, Mease P, Deodhar A, Maksymowych $W P$, et al. Ixekizumab, an interleukin-17A antagonist in the treatment of ankylosing spondylitis or radiographic axial spondyloarthritis in patients previously untreated with biological disease-modifying anti-rheumatic drugs (COAST-V): 16 week results of a phase 3 randomised, double-blind, active-controlled and placebo-controlled trial. Lancet Lond Engl 2018;392:2441-51.

[67] Heijde D van der, Baraliakos X, Hermann K-GA, Landewé RBM, Machado PM, Maksymowych WP, et al. Limited radiographic progression and sustained reductions in MRI inflammation in patients with axial spondyloarthritis: 4-year imaging outcomes from the RAPID-axSpA phase III randomised trial. Ann Rheum Dis 2018;77:699-705.

[68] van der Heijde D, Deodhar A, Wei JC, Drescher E, Fleishaker D, Hendrikx T, et al. Tofacitinib in patients with ankylosing spondylitis: a phase II, 16-week, randomised, placebo-controlled, dose-ranging study. Ann Rheum Dis 2017;76:1340-7.

[69] Dougados M, van der Heijde D, Sieper J, Braun J, Maksymowych WP, Citera G, et al. Symptomatic efficacy of etanercept and its effects on objective signs of inflammation in early nonradiographic axial spondyloarthritis: a multicenter, randomized, double-blind, placebocontrolled trial. Arthritis Rheumatol Hoboken NJ 2014;66:2091-102.

[70] Sieper J, van der Heijde D, Dougados M, Mease PJ, Maksymowych WP, Brown MA, et al. Efficacy and safety of adalimumab in patients with non-radiographic axial spondyloarthritis: results of a randomised placebo-controlled trial (ABILITY-1). Ann Rheum Dis 2013;72:815-22.

[71] Maksymowych WP, Salonen D, Inman RD, Rahman P, Lambert RGW, CANDLE Study Group. Low-dose infliximab $(3 \mathrm{mg} / \mathrm{kg}$ ) significantly reduces spinal inflammation on magnetic resonance imaging in patients with ankylosing spondylitis: a randomized placebo-controlled study. J Rheumatol 2010;37:1728-34.

[72] Krabbe S, Sørensen IJ, Jensen B, Møller JM, Balding L, Madsen OR, et al. Inflammatory and structural changes in vertebral bodies and posterior elements of the spine in axial spondyloarthritis: construct validity, responsiveness and discriminatory ability of the anatomy-based CANDEN scoring system in a randomised placebo-controlled trial. RMD Open 2018;4:e000624.

[73] Weber U, Zubler V, Zhao Z, Lambert RGW, Chan SM, Pedersen SJ, et al. Does spinal MRI add incremental diagnostic value to MRI of the sacroiliac joints alone in patients with nonradiographic axial spondyloarthritis? Ann Rheum Dis 2015;74:985-92.

[74] Ez-Zaitouni Z, Bakker PA, van Lunteren M, de Hooge M, van den Berg R, Reijnierse M, et al. The yield of a positive MRI of the spine as imaging criterion in the ASAS classification criteria for axial spondyloarthritis: results from the SPACE and DESIR cohorts. Ann Rheum Dis 2017;76:1731-6. 
[75] Blachier M, Coutanceau B, Dougados M, Saraux A, Bastuji-Garin S, Ferkal S, et al. Does the site of magnetic resonance imaging abnormalities match the site of recent-onset inflammatory back pain? The DESIR cohort. Ann Rheum Dis 2013;72:979-85.

[76] de Hooge M, de Bruin F, de Beer L, Bakker P, van den Berg R, Ramiro S, et al. Is the Site of Back Pain Related to the Location of Magnetic Resonance Imaging Lesions in Patients With Chronic Back Pain? Results From the Spondyloarthritis Caught Early Cohort. Arthritis Care Res 2017;69:717-23.

[77] Machado PM, Deodhar A. Treat-to-target in axial spondyloarthritis: gold standard or fools' gold? Curr Opin Rheumatol 2019;31:344-8.

[78] Bremander A, Petersson IF, Bergman S, Englund M. Population-based estimates of common comorbidities and cardiovascular disease in ankylosing spondylitis. Arthritis Care Res 2011;63:550-6.

[79] Maillefert JF, Aho LS, El Maghraoui A, Dougados M, Roux C. Changes in bone density in patients with ankylosing spondylitis: a two-year follow-up study. Osteoporos Int J Establ Result Coop Eur Found Osteoporos Natl Osteoporos Found USA 2001;12:605-9.

[80] Haroon NN, Sriganthan J, Al Ghanim N, Inman RD, Cheung AM. Effect of TNF-alpha inhibitor treatment on bone mineral density in patients with ankylosing spondylitis: a systematic review and meta-analysis. Semin Arthritis Rheum 2014;44:155-61.

[81] Kim K, Pak K, Kim I-J, Kim S-J, Sohn DH, Kim A, et al. Association of Regional Bone Synthetic Activities of Vertebral Corners and Vertebral Bodies Quantified Using 18F-Fluoride Positron Emission Tomography with Bone Mineral Density on Dual Energy X-ray Absorptiometry in Patients with Ankylosing Spondylitis. J Clin Med 2020;9.

[82] Feldtkeller E, Khan MA, van der Heijde D, van der Linden S, Braun J. Age at disease onset and diagnosis delay in HLA-B27 negative vs. positive patients with ankylosing spondylitis. Rheumatol Int 2003;23:61-6.

[83] van den Berg R, Lenczner G, Feydy A, van der Heijde D, Reijnierse M, Saraux A, et al. Agreement between clinical practice and trained central reading in reading of sacroiliac joints on plain pelvic radiographs. Results from the DESIR cohort. Arthritis Rheumatol Hoboken NJ 2014;66:2403-11.

[84] Christiansen AA, Hendricks O, Kuettel D, Hørslev-Petersen K, Jurik AG, Nielsen S, et al. Limited Reliability of Radiographic Assessment of Sacroiliac Joints in Patients with Suspected Early Spondyloarthritis. J Rheumatol 2017;44:70-7.

[85] Hollingsworth PN, Cheah PS, Dawkins RL, Owen ET, Calin A, Wood PH. Observer variation in grading sacroiliac radiographs in HLA-B27 positive individuals. J Rheumatol 1983;10:24754. 
[86] Mau W, Zeidler H, Mau R, Majewski A, Freyschmidt J, Deicher H. Outcome of possible ankylosing spondylitis in a 10 years' follow-up study. Clin Rheumatol 1987;6 Suppl 2:60-6.

[87] Sampaio-Barros PD, Bertolo MB, Kraemer MH, Marques-Neto JF, Samara AM. Undifferentiated spondyloarthropathies: a 2-year follow-up study. Clin Rheumatol 2001;20:201-6.

[88] Oostveen J, Prevo R, den Boer J, van de Laar M. Early detection of sacroiliitis on magnetic resonance imaging and subsequent development of sacroiliitis on plain radiography. $A$ prospective, longitudinal study. J Rheumatol 1999;26:1953-8.

[89] Bennett AN, McGonagle D, O'Connor P, Hensor EMA, Sivera F, Coates LC, et al. Severity of baseline magnetic resonance imaging-evident sacroiliitis and HLA-B27 status in early inflammatory back pain predict radiographically evident ankylosing spondylitis at eight years. Arthritis Rheum 2008;58:3413-8.

[90] Molnar C, Scherer A, Baraliakos X, Hooge M de, Micheroli R, Exer P, et al. TNF blockers inhibit spinal radiographic progression in ankylosing spondylitis by reducing disease activity: results from the Swiss Clinical Quality Management cohort. Ann Rheum Dis 2018;77:63-9.

[91] Bakker PAC, van den Berg R, Lenczner G, Thévenin F, Reijnierse $M$, Claudepierre P, et al. Can we use structural lesions seen on MRI of the sacroiliac joints reliably for the classification of patients according to the ASAS axial spondyloarthritis criteria? Data from the DESIR cohort. Ann Rheum Dis 2017;76:392-8.

[92] Weber U, Lambert RGW, Østergaard M, Hodler J, Pedersen SJ, Maksymowych WP. The diagnostic utility of magnetic resonance imaging in spondylarthritis: an international multicenter evaluation of one hundred eighty-seven subjects. Arthritis Rheum 2010;62:3048-58.

[93] Schueller-Weidekamm C, Mascarenhas VV, Sudol-Szopinska I, Boutry N, Plagou A, Klauser $A$, et al. Imaging and interpretation of axial spondylarthritis: the radiologist's perspective-consensus of the Arthritis Subcommittee of the ESSR. Semin Musculoskelet Radiol 2014;18:265-79.

[94] Baraliakos X, Sieper J, Chen S, Pangan AL, Anderson JK. Non-radiographic axial spondyloarthritis patients without initial evidence of inflammation may develop objective inflammation over time. Rheumatol Oxf Engl 2017;56:1162-6.

[95] Baraliakos X, Brandt J, Listing J, Haibel H, Sörensen H, Rudwaleit M, et al. Outcome of patients with active ankylosing spondylitis after two years of therapy with etanercept: clinical and magnetic resonance imaging data. Arthritis Rheum 2005;53:856-63.

[96] Rudwaleit M, Baraliakos X, Listing J, Brandt J, Sieper J, Braun J. Magnetic resonance imaging of the spine and the sacroiliac joints in ankylosing spondylitis and undifferentiated spondyloarthritis during treatment with etanercept. Ann Rheum Dis 2005;64:1305-10. 
[97] Lambert RGW, Salonen D, Rahman P, Inman RD, Wong RL, Einstein SG, et al. Adalimumab significantly reduces both spinal and sacroiliac joint inflammation in patients with ankylosing spondylitis: a multicenter, randomized, double-blind, placebo-controlled study. Arthritis Rheum 2007;56:4005-14.

[98] Baraliakos X, Borah B, Braun J, Baeten D, Laurent D, Sieper J, et al. Long-term effects of secukinumab on MRI findings in relation to clinical efficacy in subjects with active ankylosing spondylitis: an observational study. Ann Rheum Dis 2016;75:408-12.

[99] Dougados M, van der Heijde D, Sieper J, Braun J, Citera G, Lenaerts J, et al. Effects of LongTerm Etanercept Treatment on Clinical Outcomes and Objective Signs of Inflammation in Early Nonradiographic Axial Spondyloarthritis: 104-Week Results From a Randomized, Placebo-Controlled Study. Arthritis Care Res 2017;69:1590-8.

[100] Maksymowych WP, Wichuk S, Dougados M, Jones HE, Pedersen R, Szumski A, et al. Modification of structural lesions on MRI of the sacroiliac joints by etanercept in the EMBARK trial: a 12-week randomised placebo-controlled trial in patients with non-radiographic axial spondyloarthritis. Ann Rheum Dis 2018;77:78-84.

[101] Maksymowych WP, Dougados M, van der Heijde D, Sieper J, Braun J, Citera G, et al. Clinical and MRI responses to etanercept in early non-radiographic axial spondyloarthritis: 48-week results from the EMBARK study. Ann Rheum Dis 2016;75:1328-35.

[102] Pedersen SJ, Weber U, Said-Nahal R, Sørensen IJ, Loft AG, Kollerup G, et al. Structural progression rate decreases over time on serial radiography and magnetic resonance imaging of sacroiliac joints and spine in a five-year follow-up study of patients with ankylosing spondylitis treated with tumour necrosis factor inhibitor. Scand J Rheumatol 2019;48:18597.

[103] Navarro-Compán V, Ramiro S, Landewé R, Dougados M, Miceli-Richard C, Richette $P$, et al. Disease activity is longitudinally related to sacroiliac inflammation on $\mathrm{MRI}$ in male patients with axial spondyloarthritis: 2-years of the DESIR cohort. Ann Rheum Dis 2016;75:874-8.

[104] Braun J, Baraliakos X, Hermann K-GA, van der Heijde D, Inman RD, Deodhar AA, et al. Golimumab reduces spinal inflammation in ankylosing spondylitis: MRI results of the randomised, placebo- controlled GO-RAISE study. Ann Rheum Dis 2012;71:878-84.

[105] Machado P, Landewé RBM, Braun J, Baraliakos X, Hermann K-GA, Hsu B, et al. MRI inflammation and its relation with measures of clinical disease activity and different treatment responses in patients with ankylosing spondylitis treated with a tumour necrosis factor inhibitor. Ann Rheum Dis 2012;71:2002-5.

[106] Kiltz U, Baraliakos X, Karakostas P, Igelmann M, Kalthoff L, Klink C, et al. The degree of spinal inflammation is similar in patients with axial spondyloarthritis who report high or low levels of disease activity: a cohort study. Ann Rheum Dis 2012;71:1207-11. 
[107] Smolen JS, Schöls M, Braun J, Dougados M, FitzGerald O, Gladman DD, et al. Treating axial spondyloarthritis and peripheral spondyloarthritis, especially psoriatic arthritis, to target: 2017 update of recommendations by an international task force. Ann Rheum Dis 2018;77:317.

[108] Arnbak B, Grethe Jurik A, Hørslev-Petersen K, Hendricks O, Hermansen LT, Loft AG, et al. Associations Between Spondyloarthritis Features and Magnetic Resonance Imaging Findings: A Cross-Sectional Analysis of 1,020 Patients With Persistent Low Back Pain. Arthritis Rheumatol Hoboken NJ 2016;68:892-900.

[109] Ziegeler K, Eshkal H, Schorr C, Sieper J, Diekhoff T, Makowski MR, et al. Age- and Sexdependent Frequency of Fat Metaplasia and Other Structural Changes of the Sacroiliac Joints in Patients without Axial Spondyloarthritis: A Retrospective, Cross-sectional MRI Study. J Rheumatol 2018;45:915-21.

[110] Seven S, Østergaard M, Morsel-Carlsen L, Sørensen IJ, Bonde B, Thamsborg G, et al. Magnetic Resonance Imaging of Lesions in the Sacroiliac Joints for Differentiation of Patients With Axial Spondyloarthritis From Control Subjects With or Without Pelvic or Buttock Pain: A Prospective, Cross-Sectional Study of 204 Participants. Arthritis Rheumatol Hoboken NJ 2019;71:2034-46.

[111] Baraliakos X, Thomaschoff J, Fruth M, Braun J. Op0032 Localization and Morphology of Magnetic Resonance Imaging Features of Pathologic Changes in the Sacroiliac Joints Suggestive of Axial Spondyloarthritis - a Systematic Comparison of Patients and Controls with Chronic Back Pain. Ann Rheum Dis 2019;78:85-6.

[112] Diekhoff T, Greese J, Sieper J, Poddubnyy D, Hamm B, Hermann K-GA. Improved detection of erosions in the sacroiliac joints on MRI with volumetric interpolated breath-hold examination (VIBE): results from the SIMACT study. Ann Rheum Dis 2018;77:1585-9.

[113] Baraliakos X, Hoffmann F, Deng X, Wang Y, Huang F, Braun J. Detection of erosions in the sacroiliac joints of patients with axial spondyloarthritis using the magnetic resonance imaging VIBE technique. J Rheumatol 2019.

[114] Chen M, Bird P, Jans L. Emerging Imaging Techniques in Spondyloarthritis: Dual-Energy Computed Tomography and New MRI Sequences. Rheum Dis Clin North Am 2020;46:287-96.

[115] Boy FN, Kayhan A, Karakas HM, Unlu-Ozkan F, Silte D, Aktas I. The role of multi-parametric MR imaging in the detection of early inflammatory sacroiliitis according to ASAS criteria. Eur J Radiol 2014;83:989-96.

[116] Beltran LS, Samim M, Gyftopoulos S, Bruno MT, Petchprapa CN. Does the Addition of DWI to Fluid-Sensitive Conventional MRI of the Sacroiliac Joints Improve the Diagnosis of Sacroiliitis? AJR Am J Roentgenol 2018;210:1309-16. 
[117] Bloem JL, Reijnierse M, Huizinga TWJ, van der Helm-van Mil AHM. MR signal intensity: staying on the bright side in MR image interpretation. RMD Open 2018;4:e000728.

[118] Huang $H$, Zhang $Y$, Zhang $H$, Chen J, Zheng $Q$, Cao D, et al. Qualitative and quantitative assessment of sacroiliitis in axial spondyloarthropathy: can a single T2-weighted dixon sequence replace the standard protocol? Clin Radiol 2020;75:321.e13-321.e20.

[119] Raynal M, Bouderraoui F, Ouichka R, Melchior J, Morel O, Blum A, et al. Performance of 18F-sodium fluoride positron emission tomography with computed tomography to assess inflammatory and structural sacroiliitis on magnetic resonance imaging and computed tomography, respectively, in axial spondyloarthritis. Arthritis Res Ther 2019;21.

[120] Bruijnen STG, van der Weijden MAC, Klein JP, Hoekstra OS, Boellaard R, van Denderen JC, et al. Bone formation rather than inflammation reflects ankylosing spondylitis activity on PETCT: a pilot study. Arthritis Res Ther 2012;14:R71.

[121] Buchbender C, Ostendorf B, Ruhlmann V, Heusch P, Miese F, Beiderwellen K, et al. Hybrid 18F-labeled Fluoride Positron Emission Tomography/Magnetic Resonance (MR) Imaging of the Sacroiliac Joints and the Spine in Patients with Axial Spondyloarthritis: A Pilot Study Exploring the Link of MR Bone Pathologies and Increased Osteoblastic Activity. J Rheumatol 2015;42:1631-7.

[122] Fischer DR, Pfirrmann CWA, Zubler V, Stumpe KDM, Seifert B, Strobel K, et al. High bone turnover assessed by $18 \mathrm{~F}$-fluoride $\mathrm{PET} / \mathrm{CT}$ in the spine and sacroiliac joints of patients with ankylosing spondylitis: comparison with inflammatory lesions detected by whole body MRI. EJNMMI Res 2012;2:38.

[123] Bruijnen STG, Verweij NJF, van Duivenvoorde LM, Bravenboer N, Baeten DLP, van Denderen $\mathrm{CJ}$, et al. Bone formation in ankylosing spondylitis during anti-tumour necrosis factor therapy imaged by 18F-fluoride positron emission tomography. Rheumatol Oxf Engl 2018;57:631-8.

[124] Idolazzi L, Salgarello M, Gatti D, Viapiana O, Vantaggiato E, Fassio A, et al. 18F-fluoride $\mathrm{PET} / \mathrm{CT}$ for detection of axial involvement in ankylosing spondylitis: correlation with disease activity. Ann Nucl Med 2016;30:430-4.

[125] Parghane RV, Singh B, Sharma A, Singh H, Singh P, Bhattacharya A. Role of 99mTcMethylene Diphosphonate SPECT/CT in the Detection of Sacroiliitis in Patients with Spondyloarthropathy: Comparison with Clinical Markers and MRI. J Nucl Med Technol 2017;45:280-4.

[126] Carron P, Renson T, de Hooge M, Lambert B, De Man K, Jans L, et al. Immunoscintigraphy in axial spondyloarthritis: a new imaging modality for sacroiliac inflammation. Ann Rheum Dis 2020;79:844-6. 
[127] Krabbe S, Eshed I, Gandjbakhch F, Pedersen SJ, Bird P, Mathew AJ, et al. Development and Validation of an OMERACT MRI Whole-Body Score for Inflammation in Peripheral Joints and Entheses in Inflammatory Arthritis (MRI-WIPE). J Rheumatol 2019;46:1215-21.

[128] Krabbe S, Eshed I, Juul Sørensen I, Jensen B, Møller JM, Balding L, et al. Whole-body Magnetic Resonance Imaging Inflammation in Peripheral Joints and Entheses in Axial Spondyloarthritis: Distribution and Changes during Adalimumab Treatment. J Rheumatol 2019.

[129] Renson T, Carron P, Krabbe S, Jans L, Craemer A-SD, Hooge M de, et al. FRI0214 Clinical evaluation correlates poorly with ultrasound and magnetic resonance imaging of joints and entheses in early peripheral spondyloarthritis. Ann Rheum Dis 2018;77:648-648.

[130] Krabbe S, Østergaard M, Eshed I, Sørensen IJ, Jensen B, Møller JM, et al. Whole-body Magnetic Resonance Imaging in Axial Spondyloarthritis: Reduction of Sacroiliac, Spinal, and Entheseal Inflammation in a Placebo-controlled Trial of Adalimumab. J Rheumatol 2018;45:621-9.

[131] Krabbe S, Østergaard M, Eshed I, Sørensen IJ, Møller J, Jensen B, et al. FRI0591 Wholebody mri demonstrates reduction of inflammation in peripheral joints and entheses during tnf-inhibitor treatment in patients with axial spondyloarthritis, but also age-dependent persistent inflammation in joints prone to osteoarthritis. Ann Rheum Dis 2018;77:819-819.

[132] Karpitschka M, Godau-Kellner P, Kellner H, Horng A, Theisen D, Glaser C, et al. Assessment of therapeutic response in ankylosing spondylitis patients undergoing anti-tumour necrosis factor therapy by whole-body magnetic resonance imaging. Eur Radiol 2013;23:1773-84.

[133] Wu H, Zhang G, Shi L, Li X, Chen M, Huang X, et al. Axial Spondyloarthritis: Dual-Energy Virtual Noncalcium CT in the Detection of Bone Marrow Edema in the Sacroiliac Joints. Radiology 2019;290:157-64. 